\title{
Health Status of Tribals of Rajasthan
}

\author{
Veena Bhasin \\ Department of Anthropology, University of Delhi, Delhi 110 007, India
}

KEYWORDS Health; illness; healing; social values; social relations; ethno-medicine

\begin{abstract}
The study deals with human settlements and amenities available among six tribal groups of Rajasthan in relation to its population structure and health status. Cultural processes play explicit part in sickness and health. The four main areas of human settlements: dwelling units, essential services, community's facilities and public utilities, and some major groups of factors affecting the health status of the community like Medical systems; Health services; Health and development; and Development and health have been identified. Other factors affecting the health of the tribals are historical, socio-cultural, economic and developmental. Traditional medical knowledge is coded in to household cooking practices, home remedies; ill health prevention and health maintenance beliefs and routines. The tribal response to health problems reveal a multiple and simultaneous usage of home remedies and multiple therapy. The various practitioners whose services are sought are spiritist (Bhopa, Devala) traditional herbalists (Jaankar) Jaangar) and public health practitioners. In view of lack of communication facilities and distance of health institutions from the villages, medical aid is not availed by tribals except in serious cases. Despite opening up of Public Health Centres and massive propaganda, traditional ideas of disease and health prevail. The indigenous medical system has sustained in society's social cultural complexes through deeply rooted processes. The study at hand corroborates the theory that social development level and availability of various facilities leads to lower mortality rates. This study is one of many that show that traditional medical practices as well as biomedicine co-exist. The state health programmes are well intended but lack anthropological consultation. The level of knowledge about causes of illness and its treatment is of low order among tribals. The network of public health services that is in reality obtainable to tribals is decidedly lacking in terms of infrastructure and personnel. The fact that even the poor tribals use private health facilities in preference to Primary Health Centre is an indication of the failure of the public health delivery system However, until health awareness at the household and community level improves, success in upgrading health services, though necessary will be of little service. Cultural and social factors erect the barriers to the utilisation of health care. Health and education should be paired and developed side by side. While designing a health strategy for these tribals economic and social issues need to be tackled. In addition, distinction between supply of and access to health care should abide by. Access implies locational, economic and social access; access also implies access to quality health care as opposed to the mere physical presence of a health care facility. Among tribals of Rajasthan even locational access, let alone economic and social access, is beyond the majority of the population as is evidenced by the data on the distribution of health care facilities. The most important need among tribals is to bring about changes in the social attitude to biomedicine and health care. Given the social environment of the tribal areas, this could be achieved by social intervention to overcome social or psychological resistance. In these areas caste rigidities and social stratification are still rampant and social access is still a critical factor in access to health.
\end{abstract}

This paper is a concluding section of the project "Human Settlements, Human Activities and Health Among Tribals of Rajasthan. In Rajasthan, both historical and contemporary social, economic and political conditions are responsible for the present state of affairs. The study deals with human settlements and amenities available among six tribal groups namely, the Bhils, the Kathodi, the Damor, the Garasia, the Mina and the Sahariyas inhabiting districts of Udaipur, Dungarpur, Sirohi, Sawai Madhopur and Baran of Rajasthan in relation to its population structure and health status. Human settlements are territorially bounded social system or subsystems (economic, material culture, religious, political, ethical, educational, legal, social reproductive etc.) serving a resident population. The study deals with complex issues of health and disease; and recognition of the processes by which these tribals identify sickness and the ways to thwart it. Beliefs about sickness, health and curing comprise a medical system and medical systems are part of the cultural system of any group. Medical systems surface from efforts to combat disease and conquer death, and are social and cultural responses to illness and sick role.

It is generally presumed that tribals in India tend to be healthy, living as they do in unpolluted surroundings away from the stresses and strains of modern living. This no longer holds good as evident from the numerous health reports on tribal communities. It is indeed disturbing that sufficient data regarding tribal health is not available with the government itself. Different studies (RoyBurman, 1986; Mukherjee, 1986; Rijvi, 1986; Bardhan, 1989; Basu, 1990) have explained health status of tribals with the help of morbidity, mortality and health statistics. The plight of tribals 
whose health parameters are already well below the national average is worsening. One of the basic factors which affect the tribal health is the physical environment from which majority of them draw their sustenance. Degraded eco-systems are no longer able to support tribal population, many of whom have registered a higher growth rate than the national average. The diseases which can be easily cured, assume epidemic proportion among tribals because of isolation of their habitats, illiteracy and lack of access to medical care.

Reliable and comprehensive data on disease level, patterns and trends in tribal areas are required to monitor local epidemics and to assess the effectiveness of public health programmes and prevention and control of diseases. In most tribal communities, medical care, treatment and aetiology of disease are defined with in the social context. It is important to identify processes by which tribals recognise sickness and the ways to counteract it. The illness could well be attributed to the evil eye, magic or offending some deity, the treatment for which could be through folk medicine or magico-religious methods. Religious rites are used mainly to treat diseases like small pox and propitiating the deity concerned most of which tribals believe can cure the plagues, which are associated with various diseases. Cultural processes play explicit part in sickness and health. Cultural and biological dimensions of human beings are interrelated. Camaroff $(1981,1983)$ has warned against treating illness as a "discrete domain of empirical inquiry". Health care/ healing systems/illness constructs "take on meaning in context, not as bounded set of activities, imposed categories or stock responses to objectified form of misfortune. An analysis of illness and idioms of distress, form of conflict resolution, and modes of therapeutic transformation demands a multidimensional assessment sensitive to coexisting health ideologies and shifts in social relations associated with modes of production, form of technology, and availability and distribution of resources, changes and population dynamics, etc." (Nichter, 1992). Unreflective empiricism applied to the study of health, illness and healing is ethnocentric, yielding "disembodied classifications of terms, whose meanings remain nominal, telling us nothing of their pragmatic use, their polysemic quality, their cultural significance" (Camaroff, 1983:9).

The field work for the study was conducted during 1997-99. The data were collected through range of methods, including personal narrations, household surveys, conversations, observation and interviews with the help of schedules in the selected villages from the five districts- Udaipur, Dungarpur, Sirohi, Swai Madhopur, and Baran of Rajasthan State since the bulk of the six tribals under study (namely Bhil, Mina, Sahariya, Garasia, Damor and Kathodis) are inhabiting these areas. The traditional medical practitioners-Bhopas, Jaangars, Devala (grain diviner) and Khoont (priest) were interviewed. Healers were observed during their treatment sessions. Structured interviews were conducted on the treatment strategies for different diseases.

No comprehensive strategy has been formulated to deal with tribal health problems, as there is not enough knowledge available on their customs, beliefs and practices, which are intimately connected with the treatment of disease. The study at hand focuses on health, sickness and therapy from the point of view of ordinary tribals of Rajasthan, real or prospective patients and their family members as well as local practitioners in relation to their settlements and amenities available. It takes in to account the socio-cultural basis of indigenous (herbal and cultural) practices as part of the health care among tribals. This document takes in to consideration (1) indigenous disease theory; (2) a health care system; (3) role of the healers and their forms of treatment; (4) treatment strategies; (5) the persistence or continuance of traditional practices. Ethnographic documentation of indigenous therapeutic beliefs and measures among tribals is helpful either basis for scheming more effective health programmes or to improve communication between health workers and patients for better compliance. Lambert (1992) has discussed popular therapeutic rituals that are "structured by what might be termed the local ethnography of certain kind of sickness".

Factors determining the health status or more precisely, 'non-health status' of a group are numerous and complex. Biological fitness refers to the health or the absence of disease in the human organism. However, biological fitness is not independent of the health in the psychological and social sense. The World Health Organization defines health in positive terms as "a state of complete mental, physical and social well-being." While this concept may appear straight forward, it does not easily lend itself to 
measurement. Consequently, to describe the levels, trends and differences in healthiness demographers measure the deviations from the health status as indicated by the levels of mortality (death) and morbidity (disease and disability). Since mortality is an unequivocal indicator of a population's health status, demographers give considerable attention to analyse patterns of mortality change and developing standard measurement techniques. Socioeconomic differentials in infant and child mortality have been consistently demonstrated in studies over the last two decades. A recent analysis of 20 Demographic and Health Surveys from developing countries, for example found that mortality risks for children under age five years born to uneducated mothers were on the average more than twice as high as risks to children born to mothers with a secondary school education (Bicego and Ahmad, 1996). Significant differences in childhood mortality risks have been reported for other indicators of family socioeconomic status as well (Rutsein, 1984; Bicego and Ahmad, 1996).

Health is a function, not only of medical care but of overall integrated development of society (cultural, economic, educational, social and political). In any empirical study it is simply not possible to determine the full set of factors affecting the health status of community members. Measurement of health status is in itself a multifaceted process. It is plagued with evils of partisanship or perceptions leading to contradictory interpretations. It is certainly a difficult task to implement or enforce objectivity in health measurement. In one of his papers Amartya Sen (1998) dealt with issues relevant in making an objective assessment of health status and ' policy issues' in promoting good health. Sen found that objectivity in measuring health status is often influenced by the personality of the questioner. Mortality is frequently used as a stand-in for overall community health status. Numbers of social scientists have used the infant mortality rate or life expectancy at birth as assesses of health status of community. It implies that morbidity and disability follow the levels and trends of mortality. However, substantial data evidence has revealed that mortality and morbidity may have differing levels, patterns and trends. In India, the state of Kerala is well known to have lowest infant and child mortality (Krishnan, 1985) and second lowest adult mortality (Murray et al., 1992). Several authors have noted that Kerala also has the highest reported rates of morbidity (Panikar and Soman, 1984; Kumar and Vaidyanathan, 1988). Murray (1998) exemplified that data for Indian states indicated that reported rate of morbidity is inversely related to the mortality rates. States with the highest mortality rate report the lowest morbidity. The United States reports much higher levels of morbidity than the highest reported data for India. Why should morbidity trends, levels and differentials deviate from mortality? Scores of clarifications have been put forward of increasing morbidity-associated with decline in mortality (Alter and Riley, 1989; Murray and Chen, 1990). Five main explanations have been specified to elucidate the patterns of higher morbidity and lower mortality. These are:- (1) aging of population due to the demographic transition; (2) declining case fatality rates; (3) frailty or selection effects; (4) declining economic costs of assuming the sick role; and (5) changing perception of health and sickness. According to theories of frailty, declining case fatality rates remove selective pressure on a population and weaker individuals are allowed to survive (Feldman, 1983; Alter and Riley, 1989). The population on average becomes more fragile.

The four main areas of human settlements: dwelling units, essential services, community's facilities and public utilities, all affect the health status of the community. Settlement pattern follows a definite system and effect health status of the inhabitants as well. However, some major groups of factors affecting the health status of the community have been identified.

(a) Environment and Settlement Pattern: (i) forest/hilly terrain, near the road/river/nallah, plateau/plain. (ii) Nucleated, dispersed.

(b) Housing Conditions and Amenities: (i) indoor environment, (ii) water supply, (iii) water drainage, (iv) waste disposal, (v) drinking water, (iv) schools, (vii) medical facilities, (viii) roads, ways and means of communication, (ix) household cleanliness, (x) community cleanliness (waste collection, common places etc.)

(c) Demographic Factors: (i) family size, (ii) age structure/dependency, (iii) sex-composition, (iv) fertility, (v) morbidity and mortality.

(d) Socio-cultural Factors: (i) household resource base as indicated by land owning status of the household, (ii) educational and 
occupational status of the parents, (iii) nutritional intake of family members, (iv) crowding level in the family.

(e) Medical systems: Health services

(f) Health and development

(g) Development and health

Other factors affecting the health of the tribals are historical, socio-cultural, economic and developmental.

\section{TRIBALS OF RAJASTHAN}

A profile of the six tribal communities in southern Rajasthan highlights considerable heterogeneity. The data was collected from villages of Udaipur, Dungarpur, Sirohi, Swaimadhopur and Baran districts. The districts of Udaipur, Dungarpur and Sirohi are situated in hilly regions of Aravalli range. These hills are traversed by small rivers. The riverbeds are fertile with good rainfall. In Udaipur district, Kotra and Jhadol tehsils (from where Bhil and Kathodi data was collected) are backward with few amenities, while theoretically available health and education facilities function only sporadically. The Swaimadhopur and Baran district from where data for Mina and Sahariya tribe was collected respectively are located in the South-eastern plateau of Rajasthan with stony and high table land. Bare rocks with no vegetation characterise areas of Baran district. The rainfall is frequent in all the districts. Amenities and services are largely available, as are a host of private health and educational facilities. However tribal villages remain at the periphery and are devoid of these facilities. The ecological conditions in the area dictate many aspects of traditional life, especially settlement pattern and disease pattern. The tribals possess poor assets, meager resources and petty means of livelihood. Small, hilly, fragmented land holdings devoid of irrigation facilities are the basic assets. The forests which were main source of their food, fodder and fuel are rapidly depleting.

In Rajasthan, the Bhils form 39 percent of the Rajasthan's tribal population and inhabit mainly the southern district of Rajasthan. Their stronghold is in Banswara followed by Dungurpur , Udaipur and Chittorgarh. Bhil is a generic term applied to a group of of physically heterogenous people, deriving its name from $\mathrm{Bil}$, meaning bow that describe their original talent and strength.

The Garasias constitute the third largest tribal group of the state of Rajasthan. They are spread in the districts of Sirohi, Udaipur and Pali. Their highest concentration is in the tehsils of Abu Road and Pindwara of Sirohi district.

The Damors, who numerically being the smallest group of all the tribes in Rajasthan, are concentrated in small pockets of the border of Gujarat, and the Simalwara, Sagwara, and Aspur tehsils of Dungurpur district (especially Simalwara) of Rajasthan.

Mina is a numerically predominant tribe of Rajasthan. They are most widely spread. In the north, they inhabit the Jaipur-Sikar belt of Shekhawati, continuing in to Alwar district in south-west. They were the original inhabitants of the area, and despite their expulsion from their earlier settlements, remained powerful militant group.

Majority of Sahariyas inhabit Shahbad and Kishanganj tehsils of Baran district. The large portion of Shahbad tehsil is surrounded by hills and forest. Sahariyas of Rajasthan have been designated as Scheduled tribe and recognised as a Primitive Tribal Group (PTG), which identified them in the state administration document as a socially disadvantaged community. They inhabit marginally productive areas of the Baran district and have little access to services and resources.

Kathodi is a small and isolated community, inhabiting Jhadol, Kotra and Kherwara tehsils of Udaipur district and Abu Road tehsil of Sirohi district of Rajasthan. The Kathodis of Rajasthan are Dhor Kathodis who have been brought to forest of southern Rajasthan for making katha by Bohra contractors from western Khandesh (For ethnographic details of the above mentioned tribals, see Bhasin, 2000, 2002, 2003, 2004, 2005).

The tribal villages under study tend to be poorly connected by roads, have severe water supply problems and are often reduced to depending on rain and river water. In the rain-fed region, agriculture does not offer a reliable and adequate source of income, is constrained by the uncertainty of water supply, and is chiefly geared to subsistence production with the main crops being wheat, maize and millet. A large numbers of men are employed in non-agricultural occupations - particularly labour.

The social field of Rajasthan is split vertically, horizontally and diagonally into caste, religious and national categories. That leaves little space to be 'Rajasthani' or 'Indian' or Adivasi (Tribal). The different tribals identify themselves accordingly and are typical examples of the chasm 
identified by government between the tribes and castes.

Owing to the nature of the socio-historical factors, these tribals occupy distinct and unequal position with regard to their access to the material resources, knowledge base and social conditions existing in society. These differentiations are one of the primary sources of existing conflicts and strong bias.

Tribals of southern Rajasthan have been subjected to processes, which have marginalised them from the dominating caste based society of Rajasthan. Historical and contemporary social, economic and political processes have helped in creating boundaries between castes and tribes. The region has been subjected to frequent conflicts and the pace of development has been chronically sluggish. Consequently, often the tribals have to face considerable obstacles, besides being affected by environmental stresses, natural calamities and various diseases. Short sighted planning and policies, delayed implementation of the projects and programmes synchronising with slackening attitudes on the part of the authorities subsequently produce constraints and difficulties for tribals. This has brought intra-regional and interregional imbalances.

On account of their environmental situation, virtually all the material needs of the tribals are limited to the resources made available by the natural environment. Forest and forest produce has been their major source of livelihood. Apart from fulfilling their two basic needs of food and shelter, the forest supply a variety of non-wood produce of substance value to local communities. Forests fulfill their economic and socio-religious needs. The forest area has slowly decreased because of its destruction by slash and burn agriculture and felling of trees in large quantities. The rich natural resources have been exploited and overused resulting in the degradation of environment.

\section{SETTLEMENTS AND ECONOMY}

In general tribal villages in Rajasthan are small and situated in the hills and forest whereas mixed and non-tribal villages are medium and large sized and situated on plains suggesting a positive corelation between settlements and economy of the community. Out of the villages surveyed, some were hilly, others were in close proximity to the forest, a number of these were close to the road and water source and a few were model villages, build by administration. Bhils, Garasias and some phalas (hamlets) of Damors have scattered settlements, while Minas, Sahariyas and Damors have clustered type of settlements at the foot of the hills or near fields. In the scattered settlements the huts are mostly located amidst fields. Compact shelter pattern is seen in mixed villages where both tribals and non-tribals reside. The tribal settlements in such villages are at out-skirts of the villages. The Sahariyas are clustered in their 'Saharana' away from the main revenue villages. These tribal villages are devoid of basic amenities.

Forest, land and labour are the principal economic resources of the tribals of Rajasthan; they practice mixed economy wherein they undertake gathering, collecting, subsidiary agriculture and labour activities. These economic activities are combined depending on the time and space. All the six tribal groups undertake cultivation; however agriculture production does not provide self-sufficiency to all. Gathering and collecting forest produce still remain a source of livelihood among some tribal groups. The tribals staying inside the forest or close to the forest cater to all of their needs through traditional means. This makes them socially close up to the outside world. Their socio-economic formation is the result of their dependence on forest produce, as their agricultural land with no permanent irrigation source makes agriculture tricky proposition. The tribal settlements away from the forest, adjacent to the main road are better off and are reaping the benefits of agrarian economy. The tribals of these settlements do not depend on forest produce for their sustenance and their attitude is not parochial. Ways and means of transportation and communication are better and this makes them socially open to outside world. Though their religion is a part of the indigenous system but prolonged interaction with local caste groups motivate them for internal intercourse. Some tribals call themselves Hindu by imitating certain rituals and festivals of neighbouring castes. The third type of tribal settlement is a model village constructed by the administration. These settlements are self sufficient in some sectors but in other the degree of proletarianisation is very high. The settlers are provided with agricultural land having no irrigation source. They are away from the forest and away from any water source, consequently it restrict their dependence on forest produce or on 
agriculture for year round sustenance. The tribal villages under study tend to be poorly connected by roads. They inhabit marginally productive areas and little access to services and resources. They do not seem to have any apparent substitutes of making a living to ensure their survival except labour. The government (state and center) welfare and development projects for the tribals have not benefited these groups. Households routinely plan for seasonal variations and fluctuations. The uncertainties of weather and resources pose hardships for these people who face chronic vulnerability in terms of access to resources.

It seems that the majority of the tribal population in the study area are still living in kachcha houses, in unsanitary, crowded condition without proper ventilation, separate kitchen, cattle shed, power supply and disposing the refuse/ in the immediate surroundings in the open. Either they do not have access to or are not availing the existing educational and medical facilities. Nearly all of them have a strong belief in traditional folk healers. Inadequate irrigation facilities, drought proneness, absence of marketing network as well as high degree of indebt ness are the cause of great distress. None or poor cattle breed ownership plague the tribals as well. Many are still pursuing subsistence agriculture on small landholdings with traditional methods of cultivation. Large segment of tribals are also engaged in agricultural and casual labour and consequently have to migrate to other areas for work. They are resource poor and backward in terms of low level of literacy, low access to modern technology and information (Bhasin, 2005).

Multiple activities other than multiple factors and institutions in which households are engaged characterise tribal economy. The nonmarket activities are central to household system. The tribal households mix these resources and activities across a given year according to seasonal fluctuations. It was found that the total dependency ratio is high among six groups. When dependency ratio is high, the effective labour force is the group between 15 years to 60 years who are major bread earners. Female participation in economic activities is low in all the age groups. In other parts of Rajasthan, the economic load factor (measure of ratio of non-workers to workers, in population) is high. However, in the study area it is very low as it is the least developed region of Rajasthan.

\section{Religion}

The tribals of Rajasthan have retained their deep-rooted animistic faith and totemic concepts with a high level of superstition in spite of proximity or contact with Hindus. Tribals of Rajasthan believe in a Supreme Being, who is not similar or connected to the Bhagwan of Hinduism. They worship Bhagwan under various names. Koppers traces Bhagwan to the early religion of Bhagwat which was in opposition to the Brahmanism of Veda(Koppers, 1940-41). Though having absorbed several traits of neighbouring religions, even the deities, gods and goddesses, the sphere of tribal religion has been least affected and has maintained its identity. Among tribals religion provide ethical guidelines for living, for interpreting natural events including disease, misfortunes and disasters. Anything, which cannot be explained pragmatically, is considered super-natural manifestation.

Different spirits, ghosts, gods, goddesses, deities, worship, fear, awe, reverence etc represent the religious sphere of Bhils. Images of some of these supernaturals are housed in small structures and other religious structures are open to sky. Deora is a religious structure where number of parochial deities is housed together. A Bhil deora contain images of Bhairon,Mata, Dharam Raja and Rebari Baba.

According to Garasia tradition, god is the creator (Samla); the destroyer (Savji); as well as the preserver (Hawlo). Their important gods and goddesses are Gune (god of wisdom), Kanha (Lord Krishna), Hanuman, Kala and Gora Bhairon, Dharamraj (the tantrik god), Indra and Hesnag (Sheshnag). Garasia worship three goddesses- Sheetlamata, Ambamata and clangoddesses (Gotraj). Fire is considered to be powerful and sacred as it is the means of offering sacrifice. It also gives warmth and cleared forests for Valra (slash and burn), cultivation, which they practiced at one time. The Garasias believe in Bavsies who are considered the guardians of economic prosperity and social stability. Bavsies are natural forces like sun, rain, thunder, air, water that have status between a god and a spirit. Agriculture is very important to Garasias. They worship separate Bavsies for corn, vegetation and cattle on different occasions. The Indra god is worshipped as he controls Khetta Bavsi (who looks after the fields); Jalpa Bavsi (who controls river, ponds, wells along with all creatures 
inhabiting water sources; and Megha Bavsi (clouds) and Bijri (lightening). The supernatural assistance is considered essential for success of agriculture. Garasia resort to magical practices for the protection of crops from natural calamities. Tiger and snake have also been given status of Bavsi, as they are considered powerful.

Garasias also believe in two types of Veer (spirits): Gobru (malevolent) and Bhello (benevolent). The Gobru spirits are charged with magical powers and have close relation with magicians and sorcerers. These spirits (Bhoot, Bhootni and Chudel) cause different types of diseases - locking of Jaw, blurring of eyes, headache and fever etc. Specific diseases are associated with specific Veers (For details see Meharda, 1985; Dave, 1960). According to Garasias' belief all physical ailments are caused by the annoyance or displeasure of Veers. Passions of love and hate, jealousy and envy find their way and cause headache, toothache, backache or body ache. Role of these spirits is considered Maila (dirty) and hence only dirty things are offered to them. Bhello spirits protect human beings from injury and evil influence.

Garasias practice two types of magic (Veddya) rites, maila Veddya (black magic) used for causing evil effects; and Ujla Veddya (white magic) used for curative and beneficial purpose. Magically charmed white stones are kept on the roof to avert ill effect of evil spirits and witches. Magical spells are used to divert undesirable effects of malevolent spirits. The Garasia claim that they only use Veddya (magic) for curative purposes in sterility, conception, pregnancy, delivery and child disease. They use coconut, betel nuts, lemons, Hindur (Sindoor), weapons for magical rites, which are always kept under the cover. The Garasias celebrate Nyat, a feast of honour, for their dead that are performed only on Mondays, and a stone memorial called Sura is erected after the cremation.

The Damor are polytheistic in their religious beliefs and practices. They regard Lord Shiva as the most powerful of all gods. They also worship Rama, Krishna, and Ranchodji of Eakor, Dakorji, Kuberji, Keshariaji, Kalka Mata, Hanumanji and Ganeshji. These are considered benevolent Gods. Out of these, temples of Dakorji, Kuberji and Ranchodji are located in Gujarat. In their religious beliefs the Damors have been largely influenced by Gujarati culture. Apart from these the villagers of the respective villages worship respective deities at the major festivals. All Phalas in the villages have their own goddesses - Kairing Mata/Khodiya Mata/Phuli Mata/Kalka Mata etc. The shrines of these goddesses are not made of stones but the images are placed on a two feet high alter. These deities and Khetarpal are believed to have possession over land and agriculture, and require regular offerings for smooth functioning of life. A deity of serpent of Jodhpur is also propitiated in case of snakebite. Animal sacrifice forms an important part of the socio-religious life of Damors. Goats and cocks are sacrificed in the name of Durga Mata on the occasion of each Navratri. Damors also worship Khatri Mata of Gujarat, accompanied by animals sacrifice in case of epidemic.

. Daily worship in the temples is not prevalent among Damors, though separate Bhopas for each deity is there. Damors believe in spirits and believe that death under certain circumstances is the origin of spirits. These special circumstances or peculiar situations are:- accidental death; murder, drowning of the lady; death of a virgin or pregnant lady; death of a child or if a lady is cremated with bangles. These spirits force individuals to worship and propitiate them. Damors also believe in ancestor worship and perform Shardha ceremony. Damors worship a Jhala deity during Navaratri days to immunise cattle against disease. For performing immunising ritual a rope is stung between the trees and poles on the village boundaries. Mango leaves are hung from the rope. All the cattle of the village are herded outside. A Havan is preformed and a goat is sacrificed. One by one the cattle are ushered inside this gate and holy water is sprinkled on them.

Temples and shrines form an important part of the Mina village social life. The Mina shrines are constructed on the outskirt of the village in honour of lesser deities. A few of these shrines are Palemata, Sitlamata, Piplemata. Popular Mina deity called 'Bujda' devta is housed inside Mina houses. Minas recognise Meenavatar (tenth incarnation of Lord Vishnu) as their god and Meen Matsya Gyan Mandir is being constructed at Nangal Rajasthan situated at Dausa-Lalsot road in Dawra tehsil of Jaipur district.

The Sahariyas are extremely god fearing and perform various religious rituals, rites on a regular basis to ward off evil effects. In the Saharanas, as well as in the surrounding fields, various deities - Mataji, Ganesh ji, Hanumanji, Kabot Baba, 
Baba Thakur or Thakurji, Kalimata, Sithala Mata, Jind Maharaj, Hiraman Baba, Bhaisasur, Narsing Baba, Ahu Baba and Poet Baba are worshipped. Erected stone slabs placed on Chabutras with or without carved figures represent these. Kabot Baba is worshipped for the welfare of animals. Baba Thakur is usually some ancestor or local hero, who may have been warrior, and died while fighting. Sahariyas consider Hanuman ji as village deity. Mata ji is worshipped for curing the ailing ones. The people of the surrounding villages offer prayers to Ganeshji before undertaking any work, journey as well as before sowing and harvesting the crop; the Sahariyas imitate them as well. Usually the Nathyogis perform the Pooja in the surrounding villages, but not in Saharanas. On Diwali, Sahariya worship animals. They are bathed and the cattleshed (Khirak) is cleaned properly. Thereafter Pooja and prayers are offered.

Though Kathodis belong to Bhil cultural area, they have made a clean break with tradition; they bury their dead. It is in death that Kathodis differ from the rest of the Bhils in the area. The Kathodis do not think that their practice of burying their dead makes them lesser Hindus. The Kathodis have no temples, but install images in a mud parapet built around the trunk of a sacred tree. The images are mere stones smeared with red lead and oil. They make mud horse and offer it to the god who answers their petition. The horse occupies a special position in their folklore and their stories abound in exploits of the enchanted horse.

The presiding deities of the region Hanuman ji and Durga, are invoked with as much respect and zeal as any where else. Like all other tribal and Hindu caste groups elsewhere in the region, Kathodis too meticulously observe the important festivals especially the Dussera. Bhil, Garasia and Damor make free use of liquor, flesh etc. in their worships and rituals, Kathodis refrain from using liquor and animal products (animal flesh or even clarified butter). They use either Salar gum or vegetable oil for incense or lighting lamps. Apart from Hindu gods, Kathodis worships Baba Ramdeo, a famous hero-saint of Rajasthan, a folkdeity who attract now-a-days devotees of all castes and creeds, but is worshipped especially by untouchables such as Meghwal (Bhambi, Balai), Regar, Berwa etc. Ramdeo is believed to be incarnation of Vishnu.

The religion of the tribals is the outcome of their environs. Religion has been held responsible for many differences and norms affecting the fundamental values and behavioural pattern in life including health behaviour. The popular religion of the tribals is demonolatry. There are cultural, social and psychological conditions that produce and maintain supernaturalism among tribals. Supernaturalism provides the needed explanation as cause of suffering and is emotionally satisfying. According to super naturalist explanation, suffering is caused by evil spirits, evil eye, even good spirits if not kept in good mood or neglected or offended unwittingly. The tribals believe in vast array of gods and spirits that must be propitiated at the appropriate time for the general welfare of the society. The main characteristics of the tribal religion are divination, possession, exorcism, propitiation and expiation. Spirits are propitiated by animal sacrifices and direct communication trance with them. There are different types of supernatural beings but their functions are similar. The supernaturally caused illnesses are treated by exorcism and appeasement of the spirits. They all have powers greater than man's and are either harmful or potentially harmful. The findings of the study show that the greater the extent of traditionalism in tribal society the wider is the tendency of utilising the indigenous therapeutic practices (Bhasin, 2000, 2003).

\section{DEMOGRAPHIC STRUCTURE}

The tribals of Rajasthan are still in the first stages of demographic transition facing rapid population explosion reflecting a young population structure associated with high degree of morbidity and high rates of mortality. The tribal population under study has a young age structure typical of developing regions with fertility on high side. Nearly 46 percent of the population is below 15 years and only 3.3 percent is 60 years and above. However, it may be noted that marked inter population variations exists in the study area. Sahariyas seem to have the highest percentage of child population (50.9), followed by Bhils (49.8) and Minas (44.8), while the percentage of young population among Garasias and Damor is observed relatively lower (40.2 and 40.0 respectively), that among Kathodis appears the lowest (38.6 percent). A similar trend is observed for the dependency ratios among the tribals under study. Child dependency ratio with 90.4 percent 
is pretty high as compared to old age dependency ratio of 6.4 percent. The lower old age dependency ratio is probably due to high mortality. The total dependency ratio of tribals ( 96.8 percent) is higher than the total dependency ratio in developing nations (80.5 percent) and developed regions (57.0 percent). It is even higher than the dependency ratio of India (85.4 in 1981). In India, the state of Kerala, with low fertility show low dependency load (62.0 percent) mainly due to lower proportion of children below 15 years. In the study area, only Kathodis and Garasias show lower estimates. Dependency ratios are used as approximate indicators of relative sizes of the non-working and working populations. In the study area the TDR (Total Dependency Ratio) range from a low of 68.0 percent to a high of 123.5 percent among Kathodis and Sahariyas respectively. A significant proportion of TDR comprises of Young Age Dependency, indicating high fertility of varying degrees. The YADR is lowest among Kathodis (64.0n percent) closely followed by Garasias (65.2 percent) while it is highest among Sahariyas (113.7 percent) thereby resulting in a YADR of 90.4 percent.

The Old Age Dependency ratios, on the other hand are relatively low among the populations in the study area. The Damors have the highest OAD ratio (10.5 percent) followed by Sahariyas (9.8 percent), whereas, the Kathodis have the lowest (3.1 percent) OAD ratio.

The sex ratio for the tribal population under study is estimated as 960 indicating excess of males over females. It varies from 921 among Damors to 996 among Bhils. The sex ratio of tribals in the study area is higher than the Rajasthan's sex ratio 922 and India's 933 in 2001, reflecting less gender disparity among tribals. Since the 1901 census Rajasthan has recorded a lower sex ratio than that of India although the gap between the two has reduced over the years, with its all time low 11 in 1901. The classification of a population according to sex generally influences the form and tempo of life in community. The balance between the sexes is an important aspect of population structure. Many economic and social relationships are closely related to the balance or disparity between the number of males and females. It bears the reflection to fertility, mortality and migration of the past. Furthermore, the agesex structure also influences the present and future birth, death and migration pattern of a community. The other population parameters such as occupational structure, migration rate etc. are also influenced by the ratios between the two sexes.

The crude literacy rate for the total sample is a dismal 14 percent with a large range of difference with 4.2 among Garasias to 25.3 percent among Damors. The state of Rajasthan is educationally one of the most backward states in India. Only 39 percent of the population (age 7 and above) has been found to be literate in the Census 1991, as compared to 52 percent in whole of the country and 90 percent in the state of Kerala. There is a wide gender gap in literacy in Rajasthan, with only 20 percent of females as against 55 percent of males being literate. In the study area, the same picture is revealed as well, with only 6.4 percent of females being literate, as against 22.2 percent of males. The percent age of literate males varied from a low of 6.1 percent among Kathodis to 30 percent Minas and 39 percent among Damors. Among the six tribal groups under study, female literacy rate ranges from 13.2 among Kathodis to 0.0 among Garasias. Mina with 8.4 percent literacy follows Damors (10.5 percent). Sahariyas and Bhils have female literacy rate of 4.2 and 4.8 percent, respectively. Education is of overwhelming social, economic and cultural importance even without considering its demographic implications. In addition to its general implication in social and economic development, education plays a key role in improving the status of women. The existing barriers to girls' enrolment ratios are related to the limited autonomy of women, and "deep rooted cultural beliefs and social habits that sustain gender inequality have a prolonged inertia" (United Nations, 1995a). Female autonomy associated with education is also very clearly related to demographic behaviour, affecting age at marriage, contraceptive use, fertility and child and maternal mortality (Bongaarts and Potter, 1983; Freedman, 1987).

Fertility: The Crude Birth Rate (CBR) for the present Scheduled Tribe population, on the whole is 31.5 per thousand populations. Population under study shows a high of 36.9 (Sahariyas) and 36.0 among Bhils to low of 24.0 among Minas. The CBR of tribal population under study (31.5) is lower than the CBR of Rajasthan (34.9) but higher than the demographically advanced state of Kerala (17.7) and India (24.0). The General Fertility Rate (GFR) for the tribal population under study is 141.25 i.e. 141 children have been born to every thousand women in the age group 15-49 years. 
The pattern of general fertility rates among the different tribes is similar to CBR i.e. the highest is among Sahariyas (182.69), followed by Bhils (161.43), Damors (147.37), Garasias (123.71), Kathodis (114.58) and lowest among the Minas (104.65). Fertility peaks (214.29) between 20-24 years, reflecting a pattern of early marriage and child bearing. However, fertility rate is very high (211.06) in the age group 25-29 probably implying prolonged childbearing period. Fertility rates decline considerably only after 34 years of age (66.27) but the women seem to continue to bear children till 40-44 years (45.98).

In major states of India including Rajasthan fertility peaks at 20-24 years and remains high at 25-29 years but starts declining after 30 years. In the age group 30-34 years, whereas the level of fertility is rather low in Kerala (43.2), it is quite high in the state of Uttar Pradesh (200.4), Bihar (130.8) and Rajasthan (155.6) (SRS, 1992). Among the six tribal groups, variations are noticed, while among Minas, Bhils, Damor and Garasias, the peak fertility is seen at age 25-29 years. Among Sahariyas and Kathodis the fertility seems to reach the peak at 20-24 years. The total fertility rate in the tribal population under study is 4.2 children per women. It varies from 3.2 among Minas to 5.6 among Sahariyas.

In the study area, generally tribals understand about family planning with Nasbandi. They also appreciate the association about the lesser the number of children and improvement in the quality of life in terms of food and clothing. Nevertheless modern birth control methods are not favoured and adopted. The men are not in favour of these for personal reasons and women cannot take decisions on their own. In case of sterilisation a husband can divorce his wife on grounds of sterility. Once a tribal woman is divorced on sterility grounds, it becomes difficult to get married again. However, there is no taboo against accepting modern birth control methods. Conversely, it was found that tribal women since long have been practicing indigenous methods of birth control. Tribals use herbs for controlling the birth as well as to do away with the sterility. These herbs are easily available in the vicinity and have no side effects. For doing away with the pregnancy they boil bamboo pills, old gur, leaf of Adhatoda, Adusa, Long (clove), Tulsi (basil), Carsia, Kali-mirch (black pepper), Saunth (dried ginger) and thymol and drink this concoction. To avoid any complications this should be taken within three months of the pregnancy. For spacing the children, every month the female take boiled water of cotton seeds, Cannabis sativa (Ganja) seeds and picrorhiza (Kutki) for four days after the menstruation. For permanent birth control tribal women drink juice of Gurbell, seed of castor and citron mixed with Gur (Jaggery) with water for 15 days at a stretch. During this period she is not suppose to take milk, ghee, chilies and sour things.

Personal Hygiene: The state of personal hygiene was found to be poor almost among all the tribal groups in the study area. People do not take bath regularly. When they do, they take bath in the nearby river or Nallah, which is at a distance for their home. They do not use the accessories like soap and oil. Tribals wash their clothes with mitti (sand), which instead of cleaning makes it dirtier. Children and women hair are infested with lice. The state of personal hygiene and difficulties in procuring clean drinking water may be partly responsible for the present state of health of the community. The concept of cleanliness among tribals is absent. They do not brush their teeth. They clean their teeth with mouthful of water (Kulla karna). They are in habit of smoking bidis, chillum and chewing tobacco, which leave their teeth stained with a yellow tinge. Other castes and communities residing in the neighbourhood use Neem twigs to clean their teeth except tribals who use it only in case of dental problem. Spitting at anything or anywhere or anytime is a common practice among all tribals as well as non-tribals which they practice sitting or standing. Due to uncleanness, many tribals particularly Sahariyas suffer from skin disease like scabies (Khaj) and eczema (Chaajan). As they do not understand the cause and nature of the disease, they keep touching small children with the infected hands. The tribals' habits of sharing smoke i.e. bidi and chillum help in spreading contagious diseases like tuberculosis. The constant coughing by men and women without covering their mouth and spitting right near the sitting or sleeping place in an illventilated room enhances the chance of spreading tuberculosis and other respiratory diseases. As the hearth is also in one corner of the room, the smoke of the earth fills the room, generating respiratory diseases.

Food Habits: The traditional tribal diet comes from unrefined cereals, such as maize, Jowar, Bajra. The staple food of tribals of Rajasthan is 
maize or Jowar/Bajra Roti (home made bread) and boiled Dal (pulse) or salt and chillies. Onion and buttermilk also form the part of the diet. Fat content is less in their diet. The deficiency of the essential nutrients in the diet is marked among all the groups. This major nutritional problem is due to inadequate intake of green leafy vegetables, fruits and milk. The intake of legumes and pulses that is a rich source of energy and proteins are found below Recommended Dietary Intakes per $\mathrm{cu} /$ day. A large majority of children suffer from under nutrition and specific syndromes as intake of essential constituents of food -proteins, fats, carbohydrates, iron and vitamins are inadequate and far below the Recommended Dietary Allowance. Low family income, lack of nutritional education, and prevailing dietary habits are factors responsible for prevalent malnutrition. Those suffering from malnutrition may fall easy prey to inter-current ailments as it aggravates the clinical course of many infectious diseases. Thus nutrition accounts directly or indirectly for a considerable part of ill health.

Tribals of Rajasthan are fond of liquor and narcotics. They consume Mahuri-brewed fermented flowers and fruits of Madhuca longifolia in large quantities. Amal (opium, Papaver somniferum, Bhang and Ganja, Cannabis sativa) and Datura are common hallucinogens used by tribals. The most likely effects of using hallucinogens are bronchial irritation, risks of accident while intoxicated, dependence and possible cognitive impairments with heavy, longterm use.

Disease Incidence: In Rajasthan, calamities, unusual population movements, and out breaks of disease were not uncommon even prior to the arrival of the British, and they remained so. In case of monsoon failure it results in a 'trikal' or a triple famine of food, water and fodder. People emigrate in large numbers, but find that the famine is widespread, and hence, wander aimlessly, and die in thousands. Subsequently cholera breaks out among the half starved lower castes. Under such weather conditions of drought or excessive rains of September- October there is virulent out break of fever. The area under study has also been subjected to famines in recent past and tribals have suffered a lot in terms of economic deprivation and consequently health wise.

Both infectious and contagious diseases dominate the scene. The most common diseases of the area are abdominal disorders, dysentery
(Dast), cough and cold, Acute Respiratory Disorders (Sans Chalna), fevers (Bukhar/Taap), Guinea worm (Nadu), scorpion sting, tooth and jaw diseases, urinary tract disorders, skin diseases, eye troubles and wounds. The maximum cases of malaria are reported in the month of September and October after the rainy season while typhoid and loose motions are frequently reported in summer. Most of the tribals suffer from trachoma as a result of exposure to dust. Gastroenteritis and acute respiratory infections are the greatest killers in children. Infections and nutritional deficiency cause major health problems in adult population. Reproductive health problems (antenatal, natal and post-natal) are not paid much attention and are considered as a built in part of the child bearing and child rearing. Other problems common among adult females are leucorrhoea (Safed Paani), followed by swelling, syphilis (Challe), Gonorrhoea (pus discharge). Sexually Transmitted Diseases (STD) are common, but are not reported officially.

Factors Affecting Health: Studies have shown that endogamous factors like genetics, immunity, nutritional status and health related behavior affect the incidence and outcome of disease. However the relationship between health, environment, health/settlement pattern/amenities and health/ socio-economic status cannot be denied. The relationship between health and the environment has both quantitative and qualitative aspects. Economic development without environmental control can result in considerable damage to human health and great losses in environmental quality.

The state of health in tribal groups of Rajasthan has been affected by (a) factors responsible for spreading diseases in the population and (b) factors, which affect health in an indirect way. Factors responsible for causing diseases are (i) settlement pattern (housing and state of cleanliness); (ii) personal hygiene and (iii) consumption pattern, nutrition and addiction. Factors which affect health indirectly are (i) religion and family outlook; (ii) health care system and (iii) sociocultural and economic factors.

The two main areas of human settlements; dwelling units and amenities/public utilities affect the health of the community. Tribal settlements in southern Rajasthan are a natural growth in their physical and cultural setting. The settlements are influenced by terrain, natural environment, availability of natural economic resources and culturohistorical back-ground. 
Natural resources are under increasing pressure, threatening public health and development. Water shortages, soil exhaustion, loss of forest, air and water pollution affect many parts of Rajasthan. Housing conditions and household attributes represent health environment at the household level. Type of construction, number of rooms, separate kitchen, toilet, and bathroom and cattle-shed, drainage system/sewage system, ventilation and general sanitary conditions of the surroundings all represent health environment. Approach to village by Kachcha or Pucca road is an important factor having a positive association with the health. A metalled road signifies easier access to medical facilities outside the village and conducive to survival of the sick. The kachcha dusty roads with potholes and stones, non-availability of conveyance, exorbitant rates charged by jeeps and taxis for transportation of patients to health centers have negative association with health. The survivorship is significantly associated with pucca roads and bus services. When the communication facility index is high, mortality is low.

Pucca house, with cemented and concrete floor is positively associated with proportion of surviving children. In the study area, the number of surviving children was much less in case of Kachcha house (mud/clay floor and thatched floor) as compared to puиса house. This may be reflective of the relatively better hygienic and sanitary conditions associated with pucca houses conducive to child survival. This seems true in case of the Minas, Bhils and Kathodis while Damors exhibit opposite trend, indicating that in addition to pucca houses and cleanliness, other factors are also playing their part in child survival.

Likewise, the proportion of surviving children is positively associated with separate kitchen, toilet, bathroom and cattle-shed. Out of the six tribal groups under study only Minas have these facilities and show better results in child survival. The satisfactory sanitary condition in the house and surroundings lead to greater chance of child survival, in addition to other factors. A study of United Nations Development Programme estimates 589,000 deaths due to indoor pollution (UNDP, 1998: 227). Indoor pollution is due to burning wood, animal dung, crop residues, and coal for cooking and heating. Most of the victims of indoor pollution are women and girls who have primary responsibility for cooking and looking after the house.
The size of dwelling unit is found to have an inverse relation with mortality in general. The survival ratios seem to be lower in case of one room, which leads to crowding and helps in spreading infectious diseases. This is also an economic indicator. Poor people live in one-room houses while higher social classes and economically better off have bigger houses with more than one room.

Among the six tribal groups under study, the proportion of surviving children is higher where the source of drinking water is hand pump. The water from hand pump is relatively safer than from well or tank, as these are mostly unprotected and rarely cleaned, leading to water borne diseases.

Clean drinking water and sanitation are important for human health. One quarter of the world's population lacks clean drinking water and sanitary human waste disposal. As a result, diarrhoeal diseases are endemic throughout the third world and constitute the world's major cause of infant mortality. In developing countries, unclean water, along with poor sanitation kills over 12 million people each year.

Some observers have argued that water and sanitation systems should receive higher priority than other investments, because they fundamentally improve human health. Unfortunately, clean drinking water and sanitation have not been a high priority for many countries, and India is one of them where clean drinking water is available to 42 percent of the population and waste disposal facilities are available to only 20 percent.

During the last century, in the United States and Great Britain, cholera and diarrhoea rates dropped sharply, mainly because of the improvements in sanitary conditions. Studies in California and Kentucky have revealed that compared to disease rates for children both indoor water and toilet, diarrhoea occurred twice as often in children who had outside toilets, and four times as often in children who had neither. In twenty American cities, the average reduction in typhoid fever following installation of water filtration was 65 percent (Rosenberg, 1962). A Chilean study concluded that "the availability of drinking water... cut the incidence of acute diarrhoea by about 74 percent" (Department of Rural Water Supply, National Sanitary Work, Chile).

In India, high cost and cultural barriers have blocked sanitation development. Food, housing and fuel take precedence over water purity, and 
toilets were seen as a luxury, not as a necessity (Chauhan, 1983). In tribal areas of Rajasthan also the other development programmes have taken precedence over water purity and toilets. The majority of tribals are ignorant about the causation and prevention of disease, thinking demonism as cause of illness. People do not relate disease to water supply and waste disposal.

Morbidity Pattern: Ecological factors and human settlement patterns pave the way for the outbreak of some diseases, socio-cultural and economic factors have stimulated their incidence and seasonal factors have heightened their incubations and complications and reinforced their virulence. If rain brings in the gastrointestinal disorders, summer harbinger fever, malaria and cough and the winter affect the people with infections of pneumonia, bronchitis and the respiratory diseases. High incidence of STDs and Reproductive Tract Infections (RTIs) among tribal women is cause of concern. Morbidity pattern in the study area illustrate that the incidence of disease is concentrated among children and old age people. Sickness among children aged up to five is due to diarrhoeal, respiratory and skin diseases. Most of the diseases causing sickness are highly associated with settlement pattern, crowding, poor housing and sanitation, water supply, lack of amenities and wide spread poverty. A high percentage of 12.9 have been reported under cases peculiar to infancy in Rajasthan against the national level of 9.3 percent. It has been suggested that low weight at birth is a major cause of child sickness and health. However, there are no statistics to support this, as most of the deliveries take place at homes in the area. Out of several causes of death, some are independent and some are interrelated or difficult to differentiate, some are preventive in nature, some are controllable, yet some others are beyond control. These causes may not be equally responsible for all age groups. Disease causes may be age, sex and location biased. Most of the infectious diseases can be brought under control by preventive technology i.e. implementation of safe drinking water, hygienic sanitation and effective immunization. Tetanus, measles, whooping cough and tuberculosis can be subsided by immunization. In the study area adult female population suffer from sexually transmitted diseases, antenatal, post-natal, delivery, miscarriage and abortion problems in addition to common diseases of the area.
Mortality: Crude death rate (CDR) in the present tribal populations is high (22.13) as compared to India 8.6 in 2001. Age-wise mortality shows a U-shaped curve indicating a high death rate up to the age of 14 years and after the age of 60 years. Age specific death rates show a high mortality (62.91) in the age group 0-4. The infant mortality rate among tribals is very high (224.64) as compared to India's 6 per 1000. In Rajasthan, the death rates of children aged 0-4 years have been estimated as 33.6. The death rate for children below 5 years for India according to SRS 1992 is 26.5 and child death rate varies from 3.9 in Kerala to 38.5 in Madhya Pradesh. It may be stated here that death rates are higher (84.24) among males in the age group, 0-4 years as compared to females in the same age group (43.04) among the tribal population under study. The differentials are particularly striking in the case of child survival and are pointing towards the social and economic deprivation. Environmental factors - both physical and social- are known to play a greater role in child health. Death rates can be high due to the interplay of several factors including adverse living conditions, economic and educational scenario, somewhat lesser access to bio-medical care, persistence of traditional medical beliefs and practices, traditional occupational pattern, early age at marriage and childbearing, high parity etc., the effect of small sample size cannot be ruled out completely.

Correlation of infant and child mortality (child loss per woman) with a number of independent variables has shown significant positive relationship ( $\mathrm{p}<0.05)$ with age of woman, disposal of refuse in the immediate surroundings, nuclear family structure and number of live births per evermarried woman. Older women are more prone to losing children because of age related factors. Disposal of refuse in the immediate surroundings pollute the environment generating morbid conditions. In the nuclear families, the mother is the prime caretaker. In the absence of additional kins in the house or mother's employment outside the house is not conducive to child survival. High fertility often leads to high offspring mortality and vice-versa.

Significant negative correlation $(\mathrm{p}<0.05)$ exist between infant and child mortality and education of husband and wife, age at marriage of husband and wife, size of cultivable land holdings, number of rooms, improved ways of communications.

In the study area, land ownership is an 
important criterion of social and economic status. The infant mortality differentials are related to the size of landholdings. The larger landholding size responds positively to the proportion of child survivors, reflecting relatively better socioeconomic standings, than is the case with smaller land holdings or landless families.

The proportion of surviving children in the present population groups is higher when the approach to village is pucca road. A metal led road implies ease of access to facilities outside the settlement, which is conducive to survival of children. The similar trend is observed for the individual tribe. The presence of communication facilities (post/telegraph/telephone) within $5 \mathrm{~km}$. of residence appears to affect the child survival positively indicating greater exposure to outside world and facilities. Even Sahariya, Minas and Kathodis are showing this trend. Other tribes do not have access to such a facility within $5 \mathrm{~km}$. of their residence.

General and infant mortality responds favorably to education. Survival of children depends on the education levels of both the parents. The proportions of survivors are low when the parents have only primary education and it increases with the higher education. It was observed that educational achievements of both husband and wife affected the infant mortality differentials. Children of an illiterate mother and father have lesser chances of survival, than of literate ones. The proportion of survivors is relatively higher when the education is primary. Number of studies has shown that education particularly mother's education, is important for the levels and trends of infant and child mortality of a population. The affect of mother's illiteracy on child health is mainly attributed to lesser usage of available health services like immunization. Considering the low levels of general literacy, poor access to health services and constraints imposed by socio-economic conditions curative health services are not sought. Neither 'lack of knowledge' nor 'cultural beliefs' stop tribals from looking for health care. In the present sample, the proportion of survivors increases from 0.715 , when no education facility is present within $5 \mathrm{~km}$. of residence to 0.872 when education facilities are present.

The survival ratios are also affected by the age at marriage of husband and wife. The higher age at marriage reflects greater exposure to the outside world, probably imbibing knowledge of health care practices, contraceptive usage, and benefits of small family size as well as greater chances of being educated and/or gainfully employed, all of which are conducive to child survival.

The highest proportion of surviving children is seen when the husbands are in the service sector and lower and much lower proportions are noticed when they are engaged in cultivation and labour activities. Since occupation is often a reflection of personal economic status and educational levels, it exhibits results on fertility and mortality. Along with income, it defines the socio-economic class or status of an individual. Similarly, the proportion of surviving children is found to be higher when women are engaged in cultivation or economically inactive than when they are engaged in service sector or are as labourers. This can be explained in terms of longer separation of infants or children from the mothers.

The analysis seems to indicate that there is some association between ill health and mortality with large family size. It has been shown by various studies that larger the family size, greater is the occurrence of common diseases in the family. The health of the family is affected by nutritional deficiencies. The health of mother in a large family with limited income is affected by low nutritional level and also by the physical and mental pressure associated with child bearing and child rearing. Parents in areas with high mortality rates produce more children than they desire because they want to ensure the survival of a minimum number as observed among cultivators. Subjected to repeated pregnancies these women suffer from an almost continuous nutrition drain, which exposes both mother and child to high mortality risks that show a definite increase from one pregnancy to the next. Family size is positively associated with the average number of sick members and average duration of sickness. High level of dependency in the family and high proportion of females corresponds with a higher incidence of sickness. The household survey data show the large family size has adverse effects on education and health and nutrition. In terms of educational achievements of children from large families have lower educational achievements than their counterparts in small families, although their mother's educational level and income are equally important in explaining educational differences. Such children are more likely to participate early in productive and money-earning 
activities, which are closely related to educational level achievements. Participation in labour force and employment are restricted to labour, without much skill requirements. In terms of health those from large families are likely to worse off because of poor nutrition and inability to afford medical services. Thus, there is a vicious circle difficult to break. The implementation of developmental programmes is not sufficient to break the cycle. The families themselves need to take positive steps to ensure that they are able to enjoy the benefits of development programmes.

Health Status of Women: The persistence of ill health in tribal areas is strongly correlated to social variables. Particular attention has been paid to health problems of tribal women as tribal women differ from other women of other areas due to their geographical location, historical background and the processes of social change. Here women are more vulnerable to diseases that afflict the population in general. Expectant mothers and girl children are neglected. This is borne out by analysis of indicators such as infant and child mortality, fertility and other vital rates. Health status of the tribal women is reflected by its sex ratio, female literacy, women-child ratio, and marriage practices, age at marriage, fertility, mortality, maternal and child care practices and incidence of Sexually Transmitted Infections (STIs). During the course of study 1087 women of six tribal groups in the age group 15-59, which constitute 24.8 percent of the sample, were contacted. It was found that numbers of females were suffering from some kind of infection that they were not able to identify. Some of them could recognise certain symptoms of STIs like irritation of sex-organs, yellowish-white secretion and swelling of the thigh and uterus but their knowledge of transmission of disease was poor. Likewise prevention measures were unknown. Great deal of laxity prevails in the sexual relations. Pre-marital, extra-marital and transitional unions though not appreciated but are tolerated by society. Marriage among tribals is not a religious sacrament and is comparatively free. Divorce and widow remarriage is customary. Early marriage has traditionally been the norm in tribal culture, nearly 53.3 per cent females were married by the age of 14 years; the age at marriage among Minas and Sahariya is very low.

Reproduction health problem (ant-natal and post-natal) are not paid much attention and are considered as a built in part of the child bearing and child rearing. Terminations of pregnancies are resorted in cases of pre-marital and extramarital relationship, with the help of local herbalist without attracting much attention. In the study area, pre and extra marital relations are of common place, but care is taken not to attract public attention. The studies of Malvi (1980), Vyas (1980) and Vyas (1980) also report high incidence of STDs among the tribals of Rajasthan. Tribals believe that there are three different sources from which such diseases (Sujak) may be contacted and none of it is remotely connected with sexual behaviour. These are namely: (1) if Sakkar or Gur is eaten together with the Bajri Roti (millet bread) immediately followed by drinking cold water, (ii) if a person passes urine at a wet fence where someone inflicted with Sujak has urinated before; and (iii) Sujak may be contracted from a inflected person. The folk aetiology of sexually transmitted diseases is in consonance with the socio-cultural conditions of the area. Here popular medical notions make it possible to maintain a convenient morality in matter of sexuality. These local medical notions help in maintaining clandestine extramarital sexual outlets and officially acclaimed standards of pre-marital chastity and marital social loyalties. Stability of ethical norms and culture as such is hence reinforced. The folk aetiology attributes transmission of venereal diseases to innocent sources. Tribals use charms, amulets, perform rituals to please the annoyed deities, sacrifice animals and also allows free discussion of subject quite openly in the community and medical counter measures can be taken unimpeded by shame and secrecy. So far as AIDs and HTV are concerned, tribals are least knowledgeable.

The incidence of STIs is high among societies where sexual rules are not stringent and there is laxity in social behaviour. As the level of awareness about the transmission, symptoms, consequences and prevention of sexual diseases is of low order among tribals, women suffer more than men. The problem of STIs is connected to the level of education and socio-economic characteristics of the respective population. Education by and large augments the ability to know more and form a supportive framework. The tribal women of Rajasthan have been very unfortunate, as majority of them never went to school. Alternative means of communication like community-based health forums to reach these women to improve their knowledge of sexual illness have not been considered at length. The 
crude female literacy rate among the six tribal groups under study is as follows Sahariyas $=4.2$; Minas $=8.4$; Bhils $=4.8$; Kathodis $=13.2$; Damors $=$ 10.5; Garasias $=0$. Promiscuity plus liberal attitude towards pre-marital and extra-marital sex has been accounted responsible for high incidence of STIs. (Bhasin, 2004)

Analysis reveals that education of women is the most important factor in determining maternal health, family and community health even after controlling for the availability factor. Education of a woman has a significant positive relationship to health status, as educated women are most likely to realise the benefits of using maternal health services. In addition, education may enhance female autonomy, increasing women's ability to make decisions regarding her own health and children's health.

The figures recently published by the Registrar General of India showed that 408 mothers die due to causes related to delivery out of very 1,00,000 mothers who give birth in India. The maternal mortality rate is high because of neglect of maternal and women's health. In the study area almost all the deliveries take place at home and are conducted by 'Dais' or traditional birth attendants (TBA) or relatives. Maternal mortality is high in the area but there are no reliable statistics available. Material and social deprivation is clearly the root cause. Growing up in poor or resource constraint families, eking out a hand-to-mouth existence, either they never take admission in the school or drop out early from school and join the household labour force. Girls go through early marriages and are under social pressure to start a family immediately as fertility is highly valued. Inadequate nutrition coupled with hard work or manual labour on the land and young age at marriage compromises women's health. The data show high maternal morbidity and many reproductive health problems.

In the present study, employment of women was negatively associated with the use of health services. This may be due to the fact that majority of females (58.5 percent) in the study area were reported as economically inactive. This is so, because most of the work done by tribal women under study and else where as well falls outside the purview of gainful economic activity. The traditional load of women from housekeeping to rearing children, helping in various activities, tending cattle, cleaning cattle-shed etc., even though may use up their whole day, are not considered as gainful ones i.e. wage earning ones. However, female labour is central to all economic activities among tribals. The work load that is associated with these activities most unlikely does not give women any time to seek medical care in the far away centres. Studies have shown that employment in the informal sector does not necessarily raise the status of women; it may be even negatively associated (Riley, 1997; Momsen, 1991). In tribal areas, even if women have an independent means of income they have no ability to spend on self and child health care. Income earned from labour is small and is being managed by men. Women have little time and money at their disposal, as well as lack of decision-making power to provide appropriate preventive and curative health care.

The tribal communities residing in Rajasthan are patriarchal and men anxious about their identity characterise the ideological role of women. The tribal women in the study area have been denied roles associated with masculinity as a result of the ideology of the family and kinship, which identifies paternal roles with authoritative roles. Despite their significant economic roles, women's contribution to the economies of household, family and gotra are downplayed. They are denied the ownership rights of economic resources for the reason of their marriage and subsequent change of residence. Tribal women remain dependent members of their community regardless of the significance of their labour and the institution of bride price. In spite of their central role in subsistence activities of their families, their economic power does not extend to societal or political spheres. The economic power of the women in the household is not translated in to corresponding community authority. They are not ignored at household level but are not given due credit and importance at official level. Women supremacy is restricted within the family domain and does not extend to social or political spheres. The ideology though being challenged in the mainstream caste society of Rajasthan is still persisting in tribal society. Few women who have succeeding in acquiring some positions in communal life have found that their competence and or their executive methods are frequently challenged.

As the religious sphere is most dominating among tribals it constitutes a major field for male domination in social cultural framework. The women are deprived of public authority. Religion 
legitimises gender hierarchy. The subordination of women in religious activities and their denial of access to positions of religious leadership has been a powerful tool in most world religions in supporting the patriarchal order and the exclusion of women, from the public form (Ortner, 1974; Sered, 1994, 1999; Wallace, 1997; Franzmen, 2000). The religious sphere is a major field for male domination, and a strategy to deprive women of public authority (Scott, 1988; Jones, 1993). There are few innovations in religious sphere, and hence these changes must exist within a traditional, ritual and textual structure. Religious institutions are resistant to gender equality. In structure an explicitly male religious framework contains the tribal societies. Though the secular institutions strive to eradicate inequality but it was seen that women of these areas were lagging behind in all fields.

It is well established by studies that maternal health services have a crucial role to play in improving the women's reproductive health and consequently the family and community health (Bhatia and Cleland, 1995; WHO, 1989; Magadi et al., 2000). The utilisation of health delivery services is influenced by number of factors such as availability, quality and cost. However, it cannot be said that where there is a good supply of services, demand is created in and of itself. It may happen that availability of health services may not encourage all women to avail the services; some women are much likely to use maternal health services than the others. Availability of the maternal health services is not the only explanation for using these; other factors such as social structure and status of women are crucial for underutilisation of these facilities. However among tribals of Rajasthan, many women do not seek biomedical surveillance of their pregnancies. Prenatal care facilities are often poorly synchronised and tribals do not make the most of it for a variety of reasons. There is cultural logic of proscription and prescription for pregnancy. The deliveries (Japa) among tribals are carried out in particular hut called Jhopda. Elderly ladies from neighbouhood or relations help in the birth of a child. In case of complication, help of dai-traditional birth attendant or ANM is sought.

As a result of biomedical management of pregnancy and birth, standardised norms of behaviour and actions are mandatory. According to Brigitte Jordan $(1993,1997)$ biomedicine has assumed "authoritative knowledge" over pregnancy and birth and consequently eroded the traditional forms of authority and knowledge. At the same time, it has been shown that women often resist dominant biomedical interpretations of pregnancy and birth (Jordan, 1993; Rapp, 1993; Browner and Press, 1996; Sargent and Bascope, 1996). Traditional knowledge of women is based on a women's own bodily knowledge, past experiences, information absorbed from members of her social networks, or larger socio-cultural context. Biomedical format for pregnancy may or may not be consistent with the traditional expectations. Apart from traditional thinking there are other factors that hamper the women's making use of maternity care resources. These include socioeconomic characteristics like education and wealth; distance to health centres, cost, quality of care, and perceptions of need (Thaddeus and Maine, 1994). In tribal areas under study, there is no social support and networks that encourage prenatal care usage. Perception of risk is another factor that determines the use of biomedical resources, in part because risk is itself often biomedical defined (Atkinson and Farias, 1995). Among women who perceive pregnancy and birth as only marked stages in the context of normal health, medicalisation of these reproductive events may be related in so far as biomedical intervention is seen as unnecessary, irrelevant, or even dangerous (Nichter, 1989; Nichter and Nichter, 1983). Thus in communities with strong traditions for managing pregnancy and birth, the introduction of biomedical facilities to provide prenatal care is often met with indifference (Jeffery et al., 1988).

In a study on factors influencing the under utilisation of maternal health services, it has been argued that changes in women's status have been the key to differentiate the behaviour of those seeking modern health care from those following traditional practices (Florez and Hogan, 1992). In general, women with low status are less likely to use modern facilities, whereas women with higher status make use of modern facilities for taking care of themselves and their families (Caldwell, 1996). In the study area, majority of maternal deaths takes place at home and few on the way to health centres. One of the reasons that women die even after arriving at hospital/centres is the extensive delay often caused in seeking the medical aid. Several factors were found to be deterrents to seeking timely care at the health 
centre, including women's preference to deliveries at home, the cost of transportation and hospitalisation and the women's status in the society. It was also observed that the facilities for managing emergencies and complications were generally basic in these Primary Health Centres, although these did exist in state level hospital. Low levels of maternal and health services use, poor knowledge of STIs prevention and an eminent need of medical care among these tribals suggests that the "inverse care law" proposed by Hart in 1971, still exists here. The "inverse care law" states that good medical care tends to be less readily available the more it is needed in a particular population.*

\section{Cultural Context of Health, Sickness and Medicine}

Every culture has its particular explanation for ill health. Culture provide people with ways of thinking, that are "simultaneously models of and models for reality" Geertz (1973). Religion has been held responsible for many differences and norms affecting the fundamental values and behavioural pattern in life including health behaviour. The religious beliefs of tribals are pluralistic, with both Hindu and Islamic religious perceptions being absorbed in their animistic religion. However, they consider themselves Hindu. It can be said that the popular religion of these tribals is demonolatry and in this there is no deep cleavage between the six tribal groups under the study. All of these gods, ghosts and spirits are capable of possessing people, animals and objects, and all have to be propitiated at one time or another with appropriate ceremonies. However, the belief in supernatural causes exists alongside the belief in natural causes as in case of general health problems and reproductive health problems. They are familiar with some conditions, which point to the cause, and so the treatment. Tribals are fastidious about the aetiology of the disease as this is important for therapeutic measures. Diagnosis is necessary before selecting the right treatment.

Indigenous Disease Theory: The indigenous disease theory of tribals allege that illness results from humoral imbalances stemming from diet,

*The theory of "inverse care law" is based on a study of resource allocation for health services in Wales, England, nearly 30 years before government policy began to address the situation. climate, social offences, life activities, astrological and imperceptible forces, and spirit intervention. Accidents, calamities, diseases and losses are readily explained by holding some elements of supernatural or another responsible for.

\section{Causes of Sickness}

By Humoral Imbalance: Tribals classify some diseases like colds, fevers and other respiratory infections as illnesses of cold (sardi ki bimariyan); and problems like boils, ulcers, piles, genito-urinary disorders are believed to be the illnesses of heat (garmi ki bimariyan). These illnesses are supposed to be caused by excessive internal cold or heat in the body respectively. This heat or cold does not correspond to body temperature but rather to internal humoral state. Treatment of such illnesses is always accompanied by dietary modifications.

By Spirit Intervention: Tribals believe that sickness is caused by social offences against dead or living or celestial world. Tribals allege that spirits and ghosts cause various kinds of suffering and are agents of illness and death. These include Bhairon, the main male deity, two female deities, the Kuldevi (clan mother) and Sheetla Mata (pox goddess). Most of the tribals believe that the Sheetla Mata causes smallpox. The male deity Bhairon and two female deities are considered strong and powerful, because they are accompanied by Veers (spirits). All physical ailments are caused by the annoyance and displeasures of Veers. In case of diseases like pox (Bari Mata, Choti Mata, Acparo), Miyadi bukhar (time bound diseases), Motijhara (typhoid) etc tribals are not bothered about aetiology of the ailment but of development and consequence of it. The pox diseases-small pox (Bari mata), measles (Choti Mata) and chicken pox (Acparo) are attributed to the wrath of three mother goddesses. The manifestation of the pox disease is caused by heat of her presence within the human body. Mata is considered powerful because of her connection with illness, especially fevers and pox. The goddess is both feared and respected reflecting an ambiguity between illness and sacredness. Tribals propitiate mother goddess by observing religious rituals and festivals. These propitiation rituals are well thought-out simple remedies. Tribals are aware that despite their worship their children may get inflicted with pox disease because of some mistake 
committed in ritual or worship. However, they believe that since they are observing all precautions the disease will leave the body in a specific number of days with no permanent damage. One more sickness, which is attributed to wrath of supernatural, is 'Motijhara' (typhoid). It is believed by tribals that if 'Thakur Baba' is not worshipped at a proper time, his wrath may invoke 'Motijhara'. It is a condition caused by cold in the head accompanied by high fever. In its initial stages it is mild fever that moves downwards and starts appearing on chest. This initial condition is known as 'Panijhara'. If this condition persists for longer period, it gets transformed in to 'Motijhara' that is characterised by the bad smell emitting from patient's body. For diagnosis local healers smell the palm of the patient's hand and look for 'spots' (Moti) or rash on the chest. The appearance of rash accompanied by bad smell from body is considered a necessary and expected course of disease.

By Human Intervention: Tribals of Rajasthan surmise that sickness by human intervention is possible. Magic, sorcery, evil eye of Dakan (witch) can cause damage to health, psyche and property. Among tribals Mooth, a word derived from a Moothi (closed fist) is dreaded as Voodoo sent alarms among British residents in the earlier colonial Africa. A handful of grains are kept in Moothi, charmed with magic and are sent to the person to whom Devala wants to harm. This practice is mastered in the cremation grounds or under a tree. People believe that jealousy or 'difference' as important factors for inviting Mooth, which are generally operated by Daken (witch) and churels, the evil spirits of bad women. Tribals believe that there are certain women who can instigate spirits of powerful deities or powerful humans to attack on a living soul indicating displeasure of the attacker. These spirits are considered powerful because they are highly mobile. Women are associated with both mobility and detachability (as they leave their parental home after marriage), and the Veer are frequently seem to be feminine. Locals know about such women but are afraid to provide details less they become victims themselves. At the time of crisis, Daken, always female, are singled out and punished. The empirical reality of such phenomenon is less important in comparison to the connection between occult belief and the social problem. This is a question of 'empirical' and 'rationalists' link as that between distorted perceptions and tendencies towards scapegoating. The comple-xity and multiplicity of such phenomenon (human intervention) is not simple. "Witchcraft and sorcery are best seen as occupying their own space (seemingly a hyperspace) outside of set frameworks of social or psychological analysis" (Shanafelt, 2004: 329). Bhils are familiar with witchcraft, once identified; the witches meet a severe treatment. It is believed that witches cause sickness with the help of spirits. The malevolent and evil spirits that haunt the recesses of atmosphere cause sufferance through diseases and sikotra is one such malevolent deity among Bhils.

\section{HEALTH CARE AMONG TRIBALS}

Four systems of treatment are available to them: herbal; ritual care; biomedicine and Ayurvedic beside home remedies. The State government has introduced biomedicine and Ayurvedic system of treatment. There are government sponsored Public Health Centres, private medical practitioners practicing biomedicine as well as Ayurvedic medicine (herbal and mineral tradition of Indian Medicine). The traditional healers who cater to the needs of tribals are: -specialists in home remedies; ritual care practitioners(Bhopas); herbalists (Jaangar) Jaankar) who administer 'Desi-dvai'; Nabj or Nadu (pulse) specialists; grain diviner (Devala) who help in diagnosing disease and exorcising demons from the body; bonesetters; abdominal masseurs; priests (Khoont); and midwives.. The psychosomatic treatment in tribal aetiology includes appeasement of evil spirits and forces by sacrifice of animals, by offerings of grains and liquor, use of charms and amulets depicting sacred symbols. Magical spells are used to divert the undesirable effects of evil spirits.

The process of healing is deeply embedded in culture. The conceptual consequences of sickness, diagnosis and treatment and their interaction are important in understanding and managing sickness. Sickness a fundamental assault on person and society, is a matter of the deepest human concern; affecting the life and death, it can induce deep emotional arousal. Since health care is a constant choice of individuals, their perception of available alternatives and their motivation to seek cure is important. The services of various practitioners are sought only after the diagnosis has been made. The diagnosis has two types of consequences, conceptual and physio- 
logical. Of course different treatments can have different kinds and degrees of physiological consequences. Not surprisingly, the act of healing often including intensely dramatic ritual, shares qualities of the "numinous" in religious experience-it can be ineffable, absolute and undeniable (Rappaport, 1979: 211-216). It implies that the experience of healing can be highly marked. The patient experiences some pain and goes to healer for a diagnosis, who after diagnosis suggests treatment. The actual representation of metaphors for illness and cure act upon to restore harmony to the disturbed community.

\section{Healers and Their Forms of Treatment}

Specialists in Home Remedies: The 'specialists' in home remedies are elder people who do not consider themselves healers, but suggest and give herbal remedies in case of minor sicknesses and ailments. Tribals are well versed with the plants and medicinal herbs of the surroundings, which they use in case of sickness.

Herbalists (Jaangar/Jaankar): The jaangar/ jaankar is herbalist that recommend herbal remedies and also prepare the medication. This knowledge is passed on from father to son. These specialists usually diagnose by checking the pulse $(N a b j)$ of the patient. They possess detailed knowledge of the medicinal plants and make best of its availability in the area.

Ritual Cure Practitioners: The other sets of practitioners are ritual cure practitioners-Bhopas and Devala.

Bhopa: The Bhopa is a medium attached to a deity either self selected or chosen by the deity through which supernatural manifest itself. Bhopas are ritual mediators and can communicate with super naturals. The Bhopas are approached in case of sudden illness and physical ailments that persist in spite of trying all available therapies. He reveals the wishes of the deity or spirit that he brings upon himself. Spirits manifests them, and operates as agents to meet expectations of the patron. Spiritual expectations are always based on people's implicit assumptions or intentions or goals. He acts as an exorcist in removing evil eye influence or as medicine man in recurrent cases of miscarriage, and female infertility. The Bhopa cleans a person by blowing away an illness (Jhada) with ritual cure as well. A Bhopa exercises a certain amount of spiritual authority which is often more reflective and convincing.
Devala: Devala are religious technicians who make prophesy using grains. Its performance is restricted to situations of chronic ailments where evil spirits or witchcraft is suspected as the cause of sufferance. Devala literally means a person who drives away the danger. He is a person who diagnosis the evil effects of Veers and recommends the spirits that will help in curing. As many diseases are instigated by the annoyance or displeasure of a Veer, the Devala acts as intermediary on behalf of people and turn into physician cum magician. He is a sorcerer who practices magic and magical rites and offers worship to spirits with whom he is supposed to have a direct link. He drives away the evil effects by use of magical spells and charms, whereas Bhopa wards off the danger by offering worship to gods. As Devala's services, among tribals are sought after in case of chronic ailments, among Limbus of Sikkim, rice divination is used for minor aches and pains. The patients bring a coin to Yeba (male shaman) or Yema (female shaman) and place it in a brass plate. The shaman covers the coin with a handful of rice. The rice is separated in to small six piles. Four of these piles represent the four directions and two Limbu deities. The odd and even number of rice in each pile helps determining the nature of the illness, its cause, its advent and course of action to be taken. In case of serious illness, Limbus takes clothes of the patient for divination to the shaman who goes in to trance and spell out the verdict (Bhasin, in press).

Treatment with Dabna: Tribals resort to dabna as well during the course of certain illnesses. Dabna is the stamping of the affected part of the body with a hot iron piece. Different stamping patterns are mandatory for different ailments.

University Trained Doctors: Another group of specialists who cater to the needs of tribals are Ayurvedic doctors and university trained doctors. In communities with strong traditional health care system for managing health, the introduction of biomedical facilities to provide health care is often met with indifference (Jeffery et al., 1988). However, among tribals of Rajasthan occurrence of herbal medicine, ritual cure and other healing resources (bone setting, abdomen massage, midwifery, Dabna or branding, blood cupping and disease specific mantras) do not prevent them from availing biomedical facilities.

The strength of these indigenous medical 
traditions is the fundamental knowledge or ethno medical concept that is shared by the whole community. It is understood by tribals that a lot of sicknesses have natural causes and natural courses and are treated by traditional medical practitioners. These traditional practices focus not only on cure but also on damage control measures as well to ensure speedy and uncomplicated recovery. Before starting any type of treatment one may tie charmed amulets for one cannot be always certain of physical aetiology of the illness. Tying of a charmed amulet is common preliminary act that serves two functions (i) if external agent is the cause of disease, the amulets may cure the disease. The charms also protect the individual against demonic interference. The efficacy of the amulets is generally for a limited period. (ii) An amulet may act as protection even if the cause is physical manifestation, for spirits can attack a person in physically weak state.

\section{Treatment Strategies}

Self or home treatment is usually the first step in medical care, consisting primarily of concoctions of herbs, barks of trees, flowers, roots, leaves, seeds etc. and change in diet. Traditional medical knowledge is coded in to household cooking practices, home remedies; ill health prevention and health maintenance beliefs and routines. The treatments are known to elders in the house or neighbourhood or are suggested by folk therapist. Treatment is generally a family based process, and the advice of family members or other important members of a community have a main influence on health behaviour and the form of treatment that is sought.

The strategy a person chooses for the treatment of his or her illness or that of a relative depends on personal experiences and preferences. The tribal response to health problems reveal a multiple and simultaneous usage of home remedies and multiple therapy. The various practitioners whose services are sought are spiritist (Bhopa, Devala) traditional herbalists (Jaankar/Jaangar) and public health practitioners. The public health practitioners include Ayurvedic as well as biomedical practitioners (Indian Medical Council Act formally established the Traditional Medical System, Ayurveda as one of the official component of the Natural Health Care, India).

The availability of different healers enables them to switch from one type of health practitioner to another in search of the best. The tribals who can avail the facility of biomedicine or Ayurvedic do so without being familiar with the theoretical principle of medical system. Though the economic status of the households differs, they show certain similarities in their behaviour in case of illness. They employ pluralistic strategies not perceiving any conflict among these alternatives, nor do they seem to perceive them as different systems, but rather as a variety of options, among which they can choose.

Most usage is sequential but some is simultaneous. For example, an infant who is being given prescribed medicine for diarrhoea, may also betaken concurrently to a Bhopa for the evil eye or given home remedies. Although only indigenous healers cure certain illnesses such as evil eye, this does not preclude the use of biomedicine to treat the symptoms. In Guatemalan, the symptoms are treated with biomedicine, while the cause of illness is dealt with through a folk specialist Gonzales (1966). Traditional theories of illness aetiology are often multifactorial and multilevel (i.e. immediate and ultimate levels of causation) which permits the use of different treatment resources for different causal factors and levels (Cosminsky, 1977). As reported by Cosminsky (1980) for Guatemalan plantation, pluralistic behaviour among tribal population groups is pragmatic, often based on trial and error, perceived effectiveness, uncertainly of illness causation and expectation of quick results. In addition to this empirical and pragmatic behaviour, however, is the role-played by faith in the supernatural or spiritual in curing. As a person is simultaneously a body, a self (psyche) and a social being, so are the healers of the tribals. As explained by Adams, tribal healers "pursued a dialogic, relational remedy for its patients through reciprocal relationships that encouraged community, such as in gift giving to spirits and etiologies based on real social conflicts" (Adams, 1992: 154). Among tribals of Rajasthan, Bhopas attempt to resolve sickness caused by the disorder of the "social self"; Jaangars on the other hand claim to cure diseases that arise from disorders of body by means of an elaborate diagnostic system and pharmacopoeia. The tribal healers emphasise different aspects of tribal self. Social or cultural bound syndromes (illnesses caused by the annoyed spirits, evil eye) are generally treated by ritual cleansing ceremonies (Jhada-act), and physical ailments by (Jaangar/ 
herbalist), through administration of herbal extracts. The characteristics of certain ailments points to the cause and mode of action accordingly. These "fixed-strategy diseases" (Beals, 1980: 194-95) automatically affirm to particular type of treatment. In addition these therapeutic sessions are user friendly forum. The healer is inexpensive and easily accessible and people see the God's help in curing their ills. In the tribal areas there are unregistered medical doctors called "Bengali doctor" or Gujarati doctor who are popular among tribals. These doctors are not fully qualified but know about common medicines and injections etc.

The pluralistic medical situation in tribal areas provides flexibility and fulfills different needs of the population. The folk systems are open as manifested by eclecticism of both the clients and practitioners, who adopt and adapt aspects from an array of co-existing medical traditions. This openness of folk systems, as Press (1978) point out, is manifested by the acceptance of inputs from other/alternative health systems, and also inputs from institutional sectors such as religion and the family. According to Landy (1974) the traditional healer role stands at the interstices religion, magic and social system and gain its power from this position. Tribals do not view these sessions with ritual practitioners as magical affairs. For them it is the use of spiritual powers to achieve explicit endeavor by an expert who manipulates chains of cause and effect for the betterment. This is comparable to the classical anthropological notion of magic as "belief that supernatural powers can be compelled to act in certain ways for good or evil purposes by recourse to certain formulas." (Haviland, 2003: 671).

These sessions serve their functions and the distinction between empirical reality and imagination is ambiguous. This contrasts sharply with the closeness of cosmopolitan medicine, which is "discontinuous from ordinary social process" (Press, 1978; Manning and Fabrega, 1973) and is unaccommodating to alternative systems.

A general quantitative survey on the utilisation of multiple therapy system among tribals gives an impression that they have inclination towards indigenous type. The multiple medical systems available to tribals and the options available to any specific group are many. Most tribals fail to see little conflict between medicines and healing rituals. Throughout their lifetime they have used the two (the ritual healing and herbal administrations) simultaneously. In areas where biomedical institutions are within the reach of the tribals, they do not hesitate to use the medicine in place of herbal concoctions. Tribals do not find odd to use 'medicines' alongside the rituals of Bhopa. The traditional model is an ideology shared by healer and patient.

In view of lack of communication facilities and distance of health institutions from the villages, medical aid is not availed by tribals except in serious cases. However, in some areas, despite easy accessibility, survey findings show that though villagers living in the Child Health Care (CHC) villages are adopting modern health practices, tribals living in that area resort to indigenous practices. Tribals depend on traditional folk-medicine practitioners, who besides relying upon certain occult phenomenon deal with various herbs for preparing medicines for therapeutic use. In these areas people are obsessed with the uncanny, unearthly activities of spirits, ghosts and deities. The disease thought to be caused by supernatural, demand magicoreligious remedy. The tribals resort to various magico-religious practitioners for relieving people of death and disease caused and delegated by the wrathful supernatural. Respondents while availing the allopathic medicine report high percentage distribution of mortality in the present data. However, they fail to mention that allopathic medicine was taken as a last resort or in terminal cases. It was found that deaths reported while availing the services of traditional folk practitioners was minimum or negligible because that was their first choice.

People modify pre-existing practices if the economic costs are within their reach. People are pragmatic in trying and evaluating new alternatives. In case of health behaviour the costbenefit mode of analysis and the empirical evidence help in deciding, whether it is to their advantage or not. There is a change in overt behaviour of people, but it does not necessarily explain or mean changes in the belief system. In the study area, it was found that the traditional beliefs about fertility, pregnancy and abortion have remained unchanged though some females delivered their babies at health centre. The tribals of Rajasthan despite having their traditional medical system strongly supported by beliefs and practice were when offered government sponsored medical services, accepted them and put these to test even if as a last resort. They do 
not in all cases continue to use biomedicine, but they show open mindedness in trying them out. The situation among these tribals is similar to what Wagner found among Navaho. Wagner found that Navaho, "have a very open, pragmatic and nondiscriminatory attitude towards various magico-religious options available in time of need: White medicine, traditional chant ways, peyotism and even Christian sects on reservation tend to merge in their minds into alternative and somewhat interchangeable avenues for being used" (Wagner, 1978: 4-5). Tribals' acceptance of any or a combination of these multiple medical systems depends on the individual or household decision. As far as curative medical services are concerned, these are embraced more easily than preventive services, as was seen in case of immunisation. All groups were not ready to immunise their children. Garasia refused immunisation for small pox for the fear of wrath of goddess Sheetla. Likewise, many other tribals were reluctant to receive immunisation and vaccination for other diseases, as the results of the scientific curative medicine are much more easily demonstrated than the results of the preventive medicine. "Cause and effect are easily comprehended when serious illness give way to no illness in a few hours or days, cause and effect are less easily seen when, in the case of immunization and environmental sanitation programmes no disease is followed by no disease" (Foster and Anderson, 1978: 245-246). As there are multiple medical systems available to tribals to opt for, the course of action to follow depends on the situation and condition of the sick. The strategies that underline these decisionmaking processes have come to be called the "hierarchy of resort in curative practices." (Schwartz, 1969). Among different tribal groups in Rajasthan, a sequence of resort does not seem to exist; although the trend is to begin with home remedies to Bhopa to Jaangar to biomedical doctor, as the course of the illness proceeds and become more serious. However, there is also a back and forth movement between resources or a shorten approach, often based on referrals and advice from relatives and neighbours and other practitioners, which seems to be associated with desperation over the perceived increasing severity of an illness. When a person is sick, he or his family members are primarily interested in getting his health restored, for which they unhesitatingly combine different treatments irrespective of their ontological, epistemic, moral and aesthetic foundation. Medical pluralism results out of this orientation where attainment of health is primary objective and the individual is treated in its holistic self. When one system of treatment fails to provide relief, individual moves onto another and if this treatment fails to provide relief, individual moves on to another and this is individuals or his group's choice. In fact it is customary, therefore, "for an individual to present his symptoms to his relatives and friends for their appraisal before he takes step to obtain medical treatment. The patient alone is not authorised to decide whether or not he is ill, even though he himself may be convinced that he is sick enough to warrant special attention, his inmates must still be persuaded of the seriousness of his complaints" (Foster and Anderson, 1978).

Each medical system is not only a product of particular historical milieu and cultural apparatus; it has also its own cognitive categories. Human beings caught in illness episodes are less bothered about the issue of combination; they are singularly concerned with recovery and relief. For this, distinction between 'rational' and 'nonrational' methods of diagnosis and treating illness is abolished. Here the distinction between, 'science' and 'faith' categories collapses; and so is the distinction between magic and religion. Systems of thought and explication, like astrology and Sufism, which primarily are not medical, are approached for curative as well as therapeutic purposes, on the premise that religion is to be resorted incase of suffering, and illness is a kind of suffering, the alleviation of which can be sought through prayers, touch invocation of spirits, sacrifice; libation, appeasing the unfavorable planetary configuration and wearing talisman and charms on body.

In tribal Rajasthan, there is no medicalisation of folk-medicine by western medicine-the active attempt by official providers of health care to impose a standard structure on diagnostic and curing practices as discussed by RomanucciRoss of medicine in Italy (Romanucci-Ross, 1997: 2) and by Pedersen and Barriffati (1989) for Andean countries. Bio-medical systems as a rule stand in sharp contrast to the indigenous ones, although a study done in Kerala and Punjab has suggested that there are numerous indigenous medical practitioners who used western medi-cine, including penicillin injections (Neumann et al., 1971:140-141). Despite opening up of Public Health Centres and massive propaganda, 
traditional ideas of disease and health prevail. It is believed by tribals that traditional medical system is considered to have monopoly on restoring health of the body (herbalist) or the mind (Bhopa). Among tribals, the failure of the cure did not call for questioning the efficacy of the system, but on the dissonance of ritual behaviour. The total commitment of the believers in the traditional system (which is sometimes doubted by failure) persists and so does the belief of the patient in the healer, regardless of result.

The tribal traditional medical system is based on personalistic tradition of super natural healers (Bhopas) and their ministrations and Jaangars (herbalists). The theoretical side of traditional medical system, their religious background, particularly the belief in the fear of evil spirits, healing performed according to spiritual rites explains the persistence of indigenous system. These traditional healer-diviners operate within a religious paradigm, with no printed or written material to conform or support the tradition. It is assumed that these are sanctioned by their religion but with no proof. This system works on the accepted popularity of the individual Bhopa's methods, reputation and performance. The indigenous medical system has sustained in society's social cultural complexes through deeply rooted processes. It is a set of concepts of health and illness that reflect certain values, traditions and beliefs based on people's way of life. It is a "constant process of conformity to contemporary psychological needs with in a recreated cultural identity." (Wijsen and Tanner, 2001). Levi-Strauss (1967) description of the Shaman and his healing techniques sheds light on the relationship between process and consequences of healing. The "Shaman provides a language (p. 198) and like psychoanalyst, allows the conscious and unconscious to merge". This he achieves through a shared symbolic system and curing of one sick person improves the mental health of the group. In this context, the patient performs a very important social function and validates the system by calling into play the groups sentiments and symbolic representation to have them" become embodied in real experience (pp. 180-182). For these healers, the mind, the body, and the experiential field are one. The Bhopa can best be understood as a healer of the mind and body as well as community. This is achieved through his or her status as the interpreter of symbols, those cultural instruments for perceiving and arranging reality. They are significant vectors of a force that compels mind, matter and experience (Romanucci-Ross, 1980 b). The Bhopas are specialists possessing power to heal or prevent illness and disaster. It is believed by tribals that illness emanates from a disjunction of a quasi-equilibrium maintained between man, his environment and the supernatural. An individual or super individual force can disrupt the established order. The reestablishment of the order or the return to the health can only be achieved through a healer or medicine man. The medicine man has recourse to the use of medicinal plants, animal products or minerals. In other cases, he has recourse to rituals with the help of which he goes into trance and counteracts the evil forces. Spirit possession ritual, where spirit mediums channel various gods and goddesses connected to the tribal group. Among the tribals of Rajasthan, the supreme god 'Bhagwan' does not de facto come into this act at all. With the development of the ancestor cults and heroic gods of the area, the meaning of ecstatic experience takes different form. Though they always refer to supreme god, but the deity's relationship to the activities of shamanism is missing. According to Eliade, "the shaman's activities are confined to the middle world of ancestor spirits and gods or to the underworld of demons"(Eliade, 1964). The ritual specialist enters a trance before becoming possessed by the spirit. The possession usually occurs during religious ceremonies and only lasts during the event. During voluntary possession the mediums don specific apparel, which facilitates manifestation of the spirit in their bodies. The people initially become possessed by being penetrated by the spirit in the form of an illness. Roy mentions that among Bhils all illness is believed to be caused by the supernatural, or "evil eye", and cure must be sough by a raunric (magician), but no mention is made of "trance" (Roy,1935:255). However, among the Bhils of Rajasthan, Bhopa takes the help of familiar spirit through a trance in order to diagnose disease and prescribes cures. .The afflicted tribal come to seek the guidance of the ritual specialists (who themselves are possessed by various deities) to know (discover) the cause of persistent illnesses, to resolve personal problems, to be relieved of sorcery spells and possessing demons. Spirit possession is considered a problem to be remedied through the intervention of spiritually possessed ritual specialists. "The relationships between 
people and the spirits who possess them are thus metaphors for people's social, psychological and physiological conditions" (Danforth, 1982: 60). In certain instances, spirit possession is a method by which status quo is maintained. Women gain control over their lives within a male-dominated society through the ritual possession of spirit. Demonic possession is, "a culturally constituted idiom available for women for expressing and managing their personal problems" (Nabokov, 2000: 71). Among tribals these therapeutic sessions seem to psychologically enabling actions that help tribals overcome the trauma of their lives. Both men and women try to find cure to social and physical problems by visiting a spiritual healer. Tribal women marry outside their natal villages, and for several years after their marriage, are under the control of a mother-in-law who is the domestic head. Tribal women, who fall sick or become possessed, visit Bhopa. For women, a visit to the Bhopa may become a form of resistance to male ideological domination. Lonely, tired, overworked, and sometimes undernourished, these women become sick and often possessed by spirits. The condition of tribal women is similar to that of the Malay factory workers who, feeling that they are treated "like things"; use spirit possession to protest their inhuman treatment. Ong argues that spirit possession and rites of exorcism resulting in a few days leave from factory have proliferated since 1970 (Ong, 1987: 27). Moore (1993) has discussed the spirit possession, stress related diseases and traditional healers in new insight into cultural conceptions of justice, resistance, and the role of the gender in legal pluralism in a village of Rajasthan. Women and most poor or low caste or tribal are not heard in the legal arenas. They manage conflict and negative feelings in other ways. Sickness, spirit possession, flight from affinal village, violence, and suicide are some of their avenues for the resolution of conflict. Women, who fall sick or become possessed, visit a Bhopa respond to their oppression in culturally consistent ways with their sub-ordinate female status. Traditionally, they are not expected to protest in tribal court. As an alternative, they may convert a social distress into a physical distress. Moore identifies this as a "somatization of conflict". According to Scheper -Huges and Lock (when) direct confrontation by the aggrieved and submerged sectors of society tolerated, (a) more common and self defeating strategy is to turn hostile feeling against the self (1991:416).

Lewis has suggested that women's spirit possession episodes are, "thinly disguised protest against the dominant sex." By captalising on their stress, "the victims of spirit possession called public attention to their subordinate position and sought to alleviate it" $(1971: 31,85)$. In such cases spirit metaphors divulge not only a mode of unconscious retaliation against male authority but fundamentally a sense of dislocation in human relations and a need for greater spiritual vigilance in domain reconstituted by capitalist relation of production (Ong, 1987: 207).

Possession by familial spirits is a common occurrence. These spirits usually possess their relatives at moments when ceremonial protocol at festivals such as marriage, birth ceremonies has been breached. The tribal cultures are a part of larger and older traditions that have sought out the healing powers of spirituality. Tribals go to spiritual healer for divination and a ritual for healing and pragmatic purposes. Spiritual healing serves as one of the functions of the spirit possession.

The tribal healers of southern Rajasthan are different from faith healers of Ladakh (Bhasin, 1999) and Philippines (Chesi, 1981) as they do not perform psychic surgery, 'bloody operations', reflexology and magnetic massage. In addition to spiritual healing, Ladakhi Lhama/Lhapa, extract the poison from the patient' body with the help of a meter long wooden or iron pipe. This pipe is placed on the suffering part of the body and a sticky blue substance, the considered cause of the sickness is extracted (Bhasin, 1999: 199). The Philippines faith healer performs 'bloody operations', with his fingers and materialises the substances that have caused the disease. According to the faith healer, the intensity of his thoughts causes blood to appear between his fingers and the patient's skin. Psychic surgery and bloody operations are two expressions used by healers to describe inter-vention in the course of which they produce materialisation on the surface of the patient body. Psychic surgery is not a physical phenomenon, even if the patient's skin is pierced; it is a spiritual phenomenon (Chesi, 1981:31). Faith is an important part of it as it is not the healer who affects the actual cure but God, who uses the healer as an instrument. The Bhopa of Rajasthan are similar to the 'Bon-thing' and the 'Mun' the Lepcha shamans of Sikkim. Both are different from 
other mediator in the sense that, these carry out the tasks of the priesthood as well. In both the groups, while another religion was either imposed upon or through culture contact, services of lamas and monks among Lepchas and Brahmin priests among tribals are accessible, the traditional institution of 'Bhopa' among tribals of Rajasthan and 'Bon-thing' and 'Mum' among Lepchas of Sikkim carry on (Bhasin, 1989).

There is a close relationship between spirit possession as an altered form of consciousness and parapsychology. To believers in spirit possession it provides a manifest function of the causes and effects of illness and misfortunes. Possession is a powerful belief system prevalent in many parts of the world. Spirit possession is the concept that gods, demons, or other disincarnate entities may temporarily take control of a human body, resulting in notable change in the behaviour. All spirits are not purely good or evil; the term demonic possession is commonly used is when the spirit is malignant. Unlike demonic possession where the person is thought to be taken over by the devil or his demons for harm, spirit possession is voluntary, culturally sanctioned displacement of personality. The spirits, be they deities, angels, demons or the dead ones are invited to enter a human person. Possession is used to explain unusual occurrences and behaviour. It can also explain the failure of a desired result.

The spirit possession and going in to trance ritual, despite it's outwardly trappings, is generally sought out by petitioners to achieve down to earth goals:-curing of sickness and other miseries. Trance-like state is indicative of spiritual possession. The cure involves the intercession of a spirit that has the power to expel the offending demon. The spirits use medium as vessel to help victims with their problems caused by demons. Likewise, the victims become vessels for communications for the demons. It is during exorcisms that the victims would enter a trance-like state, and channel the voice of the demons. The supernatural powers are channelised through human hosts. However these merely act as vehicle of treatment. The shaman enables the divine spirit to come in contact with the spirit, affecting the hapless victim. The shaman facilitates the encounter. Thus during the encounter the exorcist and the victim are very much alike -they are both simultaneously possessed by an alien spirit. However, there is one important difference. The patient was disinclined and taken unaware during his sleep, while attending a funeral or walking under a haunted tree or any such place. On the contrary, the shaman by virtue of his training and qualifications is in a deeper consciousness and heightened state of awareness and is not as much of the victim of the possession. His possession is voluntary and thus a participant in the spirit world. By vehemently entering this expanded state, the shaman is able to exercise a limited control over the spirit. Thus, while it is the spirit and simply spirits that can affect cure, the shaman by virtue of his ability to interact with both the world of the spirits and world of man is able to direct the consideration of spirit toward the suffering and sickness caused by possession. Possession is cured by contact with a more powerful spirits, not by expansion of consciousness from within. This is an adaptive social function, or as described by Spiro (1966: 120), it (spirit possession) is the basis of social stability in potentially unstable and disruptive social circumstances. It has the similar function that witchcraft belief, as described by Evans-Pritchard (1937: 63-83), have for many African societies. The beliefs and institutions surrounding spirit possession fulfill the function as stated by Spiro (1966, 121) of providing a "culturally approved means, for the resolution of inner conflicts (between personal desires and cultural norms" (cited from Jones, 1976). Powers of strong faith, courage and great patience are the source of healing. The ceremonies of visiting the traditional healers have established a relationship of psychological therapeutic dependence on the part of the tribals with regard to healers. This dependence on the part of the tribals with regard to healer is deeply rooted in their psyche. Medical system's degree of productivity depends on the effectiveness of its armamentarium and technical skills of the practitioners. In addition, these therapeutic sessions are user friendly forum. The healer is economical and reachable and tribal perceive the god's support in curing their ills.

The empirical reality of such phenomenon is less important in comparison to the connection between occult belief and the social problem. This is a question of 'empirical' and 'rationalists' link as that between distorted perceptions and tendencies towards scapegoating. The complexity and multiplicity of such phenomenon (human intervention) is not simple. "Witchcraft and sorcery are best seen as occupying their own space 
(seemingly a hyperspace) outside of set frameworks of social or psychological analysis" (Shanafelt, 2004: 329).

The belief in spirits as causing sickness, emanating from witches, has also been reported from multi-caste villages (Berreman, 1964; Harper, 1969; Babb1975) and in rural areas of Rajasthan (Carstairs, 1985; Lambert.1992). Comparable observations have been made from other tribal groups of Rajasthan (Bhasin, 2002, 2003, 2004); Sikkim (Bhasin, 1993, 1997); Himachal Pradesh (Bhasin, 1990) and Ladakh (Bhasin, 1997). Harmful or dissatisfied spirits (malri) afflict people with disease. In Rajasthan Malri would inflict pain through mooth spells. Studies have been carried out about different types of mooth.

Spirit possession is acknowledged as an illness among tribals of Rajasthan. When a person starts acting bizarrely or a person has a sickness that does not respond to ordinary remedies, tribals consider it as a case for ritual cure. Bhopa suspect spirit possession and makes an effort to force the spirit to reveal itself. The spirit is most often the ghost of a person who has died an unnatural/ untimely death or of a person who's after death rites have not been completed. The patient is cured by 'Jhada. Jhada is ritual sweeping or exorcising the ghost by ritual offerings or transferring the ghost to another person or thing. As spirits and ghosts cause sufferings and are agents of illness and death, nearly every village and hamlet has its local ghost, usually the shrine of a childless man, one whose funeral rites remained for some reason unperformed. Of the local ghosts some are beneficent, but others are mischievous. The system of cause, effect and cure is thus a circular and enclosed system of knowledge. The cause is a spirit, the effect is spirit possession and the cure is controlled spirit possession. The system of knowledge discloses the underlying explanation and restrains disorder, chaos and inexplicable circumstances.

Spirit possession as illness has been reported from other parts of India as well. The basic pattern of the precipitating event, behaviour during the attack, diagnosis and treatment show extensive range. There are regional differences in the way people behave during an attack; make use of spirit possession as a mechanism of controlling others; and ascription of wide range of illnesses and. misfortunes under the label of spirit possession. Freed and Freed's description of the features of victims of spirit possession of Shanti Nagar, a north Indian village near Delhi- shivering, moaning, feeling weak, loosing consciousness, going in to trance and eventually recovering (1964) is different from Opler (1958) account of eastern Uttar Pradesh in which aggression and threatened physical violence seem to dominate the attack. Though, spirit possession among the tribals is non aggressive and is a more general form of social control than in Shanti Nagar. Like eastern Uttar Pradesh, spirit possession among Bhutias involves accusation of witchcraft not common in Shanti Nagar.

The traditional health care practices are 'patient-centered' and holistic views of many factors meet more effectively the needs of the patients. Patients' views about the meaning of health, treatments, the role of emotions and healerpatient communications are important. Wide variety of emotional and spiritual factors have impact on tribal health, and that fundamental change is required in the way health care is organised and provided to take full account of this. These days' tribals do not totally rely on ritual healers; however they opt for herbal remedies as well. Compared to allopathic medicines, herbal remedies are cheaper and are easily available in the vicinity. These herbal remedies are free from side effects many tribals suffer from after taking the allopathic medicines. As in case of malaria, tribals believe that herbal infusions are trustworthy cure than quinine, which creates many other problems. In tribal areas of Rajasthan medicinal plants are an important resource for restoring health. In case of severe illness, ritual healing is vital alongside other therapies. Ritual and empiric therapies are integrated. Phytotherapeutic treatment may be recommended for the sickness diagnosed by religious technicians.

In the Bhil, Garasia and Damor settlements, as huts are scattered, these remain cut off for days during monsoon by fast flowing streams. These areas experience both drought and rains. If rains are late, tribals become full of anxiety, dreading the prospect of drought. The impending drought and floods that would follow if and when monsoon arrives, is the main worry. The land has lost its ability to hold or harness rainwater because of denuded hills. After first few showers, it tends to rush down slopes forming streams cutting off the area. The muddy drinking water causes diarrhoea and other water borne diseases. Not surprising, that most of the child deaths due to 
these illness occur during June and September when these areas are cut off and health workers are unable to reach them. The lack of pucca road and telecommunication facilities in the tribal districts hampers administrative work. There is serious problem of physical access to health services in tribal areas. Many tribal villages are dispersed over a large area as hamlets or groups of households. Frequently these service points such as a primary health centre or subcentre are without the requisite personnel to offer the required services. The personal preference or the attitude of the staff manning the service points also play a significant role in influencing the effective delivery of services. These qualitative dimensions of the availability of services are equally important as the physical access. However, there can be no denying that the root cause of abnormally high child death is poverty. Health centres in the district of Rajasthan are poorly provided. Low birth weight and delayed weaning practices are the two main reasons for the vicious circle of under nutrition and chronic infections. The tribals wait too long to start feeding their children mashed food containing green vegetables and pulses which retards growth and increases susceptibility to infectious diseases. Since the health administration at National and State level lacks in quality, there is deterioration of quality of preventive, promotive, curative and family planning services in rural and tribal areas. The present study reveals a sorry state of affairs in the health care delivery system in tribal areas. The situation is worsened by the inability to implement poverty alleviation and health improvement programmes. For instance, the Integrated Child Development Scheme (ISDS) is a miserable failure in this region. The scheme that was meant to provide an integrated package of basic health, nutrition and pre-school education to children under six years and to pregnant and lactating mothers through Aanganwadis in every village has been reduced to mere supplementary feeding programmes.

Through various development schemes, tribals are found continuously rehabilitated and given cultivable land, bringing them into the mainstream of the society and to lessen their dependence on (i) forest produce, as forests are being increasingly threatened and (ii) labour as they have been found to leave en masse to other areas.(Bhasin, 2000,2003). There is encroachment of tribal land by outsiders or locally dominant castes. Because of their low political awareness, others exploit tribals. Alienation of tribal by nontribal merchants and moneylenders is serious in this region that has a hierarchy of tribute collectors. Apart from having unproductive land with low water availability, the tribals also lack managerial skills and technical know-how. Their ignorance about modern agricultural machinery and technology results in low and uneconomical agricultural returns. In addition to the unprofitable agriculture tribals also regularly experience drought and famine related scarcity. Tribals' primary concern is to prevent impoverishment from this type of scarcity. Organisation, management and planning of tribal economy and coping strategies are always towards the goal of keeping alive and to stay out of debt. Tribals have been facing such hardships for a long time and are a deprived lot and their deprivation is not just a matter of poverty or lack of income, consumables and wealth but also one of vulnerability and exposure to vagaries of the nature and exploitation by neighbors and outsiders. It seems that the tribals have been caught in 'deprivation trap' and its five interrelated clusters of disadvantage, i.e. physical weakness, isolation, poverty, vulnerability and powerlessness (Chambers et al., 1987: 10). These clusters of disadvantages lead to social, spiritual and material deprivation.

The tribals of Rajasthan inhabit the area of the district that may be included in the 'poverty square' of India, measured according to four indicators-infant mortality, female literacy, number below poverty line and per capita net domestic product, and are centered mainly in the states of Uttar Pradesh, Bihar, Orissa and Madhya Pradesh (Chambers et al., 1989: 26). In the present Scheduled Tribe populations, the infant mortality rate is found to be rather high at 224.64 per thousand live births and female literacy rate rather low at 6.4 per cent. Among the six tribal groups in the study area, five are under below poverty line. Grinding poverty is the root cause of all problems. Poverty is identified primarily as the inability to meet minimum needs of consumption i.e. food, housing medical care and education. Frequently it is measured in absolute terms as the amount of income required for subsistence. These tribals have poor income-earning physical assets (land, capital and water), human capital assets (e.g. education and health) and entitlement to public services that enhance income and consumption. 
These tribals with modest physical assets, limited education, and feeble claims to public goods are lagging behind in health sphere as well. According to the Global Indicators for assessment of progress towards the Health For All goal, a population may be considered to have adequate Primary Health Care Service, if the following are available: (1) Safe drinking water in the home or within 15 minutes walking distance, and adequate sanitary facilities in the home or immediate vicinity. (2) Immunisation against diphtheria, tetanus, whooping cough, measles, poliomyelitis and tuberculosis. (3) Local health care including availability of 20 essential drugs, within one hour's walk or travel. (4) Trained personnel for attending pregnancy and childbirth and caring for children up to at least one year of age. The data illustrate that the area under study lags behind in all the indicators for assessing Health For All. Economic empowerment is a powerful tool against poverty. To improve the conditions of the tribals it is important to economically uplift its members and empower them to fight their own battles. Government as goodwill has not eradicated prejudices and these can be fought effectively by tribals themselves. In culture, where fertility is crucial to both men and women's sense of self worth and where children are a source of income and insurance against destitution in old age, family is not limited willingly. Large number of pregnancies i.e constant bearing and child rearing pose health problems for women. Pregnant and lactating mothers are at a clear disadvantage with regard to nutrition to both men and other women. Social discrimination against women is wide spread in developing countries where women mortality rates are high. Despite the high mortality rates in the tribal area, recorded maternal deaths in the six tribals are few. The set of children who experience bouts of sickness are those whose mothers were unable to utilise curative health services, immunisation or institutional deliveries. Mother's health status prior to pregnancy, and conditions during foetal life and early infancy profoundly influence the physical and psychosocial development of children (Falkner, 1980). Lundberg (1991) pointed out that much of the class difference in health in adults is related to economic hardship experienced during childhood, and to health related behaviour such as diet. Tribals need information, education and communication concerning the risk of repeated pregnancies and other associated danger signs in case of complications. Simultaneously, the health service delivery system needs to be upgraded.

Most of the tribals' health problems are related to unsanitary conditions and lack of education. They are preventable by public health measures. In these areas importance is given to curative measures instead of preventive ones. At present there are 205 government hospitals, 1, 0003 dispensaries, 598 primary health centres, 26684 patients and 5 medical colleges in the state. In addition there are 76 government Ayurvedic and Unani hospitals, 3147 dispensaries and 76 in patient beds. Out of these only 21 hospitals and 6857 beds are serving in the rural areas. The condition in the tribal areas is still bad where the population is dispersed over an area, which does not have easy transportation. The effectiveness of a dispensary or a hospital in such conditions is reduced in terms of both area and population covered. If medical facilities were located at far off places from the settlements, the doctor or nurse population ratio would be considerably lower than the accepted international norm. However, in some cases efficacy have little or no positive effect on the productivity of the medical system. It happens in cases where improvements in efficacy are restricted to a small number of people and have a negligible effect on levels of morbidity and mortality of the total population. Improvements in efficacy are made around urban centers for which they can make a difference. However, this means that diverting resources needed for improving the health of a larger segment of the total population. This is the situation in southern Rajasthan where the capital absorbing medical intervention demanded by urban centres siphons resources away from the primary health care needs of a much large rural population at risk. The net effect is no change in overall levels of morbidity and mortality.

The study at hand corroborates the theory that social development level and availability of various facilities leads to lower mortality rates. Health supporting facilities are supposed to have direct or indirect affect on the heath status of the people. Low death rates have been achieved in parts of India where primary health care procedures, midwifery, maternal education on breast feeding and weaning, vaccination, oral rehydration for victims of diarrhoea, and antibiotics against respiratory functions have been introduced. In the tribal areas, a subcentre 
serves populations of 3,000 and 20,000 tribals have one PHC. At the same time as, for general population, one subcentre serves 5,000 persons and one PHC provide 30,000 persons (Government of India, 1999). In tribal areas, the situation is actually worse than the figures indicate because of lack of infrastructure, supplies of medicines and availability of medical personnel. In the study area, the large segment of respondents (46 percent) have access to Medical Centre/Sub-Centre (within 5 kilometres of residence), while another 32 percent have an easy access to a Primary Health Centre/Registered Medical Practitioners and about 15 percent to a Community Health Centre/Hospital. Only 7 percent respondents do not have any medical facility within 5 kilometres of their residence. Among Sahariyas, nearly one third of the respondents do not have medical facility (except folk practitioners) within 5 kilometres of their residence. Among Damors and Garasias, though they have an access to government sponsored medical facilities, registered medical practitioners are not available to them.

Infant mortality is an indication of the social and health status of the women and children in the society and a proxy for the economic condition of a community. It is also a reflection of the availability of the health services at the grassroots level. The analysis of mortality rates of neonatal, post-natal, the infant and child mortality reveals that the distance to government dispensary, public health centre is significantly associated with the mortality rates. The rates increase as the distance of these facilities increase from the respondent's place. Other factors such as the Dai (traditional birth attendants), number of visits by field workers, occurrence of natural disasters and epidemics also show a systematic association pattern with mortality rates. The Maternal and Child Health Programme has not been successful in extending services to the target population. In terms of immunisation, very few tribals have been immunised. Survey data also show that most of the women prefer to deliver at home. It is found that proportion of surviving children less than five years is lowest where medical facilities are not available within 5 kilometres of residence. However, individual tribal groups show varying trends, indicating that other factors are also influencing child survival including faith of tribals on traditional medical care. It is found that mothers do not generally panic when a child is struck by a diarrhoeal episode, especially when such cases are associated with developmental stage of child (teething, crawling and walking). Most mothers do not seek treatment outside home until the third day. The decision making process is influenced by traditional values, distance to health facilities, availability of other pharmaceutical products and financial resources. However, treatment outside home is sought only when the episode persists and is resistant to home management techniques. Mother's decision to seek health care in biomedical facilities comes after a complicated process of choices or alternatives. Still an infant, who is being given prescribed medicine for diarrhoea, may also be taken concurrently to a Bhopa for the evil eye or treated with home remedies.

It was seen that in tribal areas where both the facilities (biomedicine and traditional) were available, the tribals often accepted and availed of the biomedical facility. However, side-by-side they also performed traditional rituals. Unfortunately, adequate medical facilities are not available in many areas and irony is that the tribals are accused of not accepting the non-existing medical facilities. Biomedicine as provided by Primary Health Centres (PHCs) is generally criticised for failing to respond to the wider emotional and spiritual needs of the patients. It is like a commodity delivered by health pro-fessionals and their assistants. Community members do not participate in its planning, implementation and evaluation. In areas where public health services are not within reach, tribals depend on folk and traditional medical care, herbs are used as medicines along with rituals to cure different diseases. The dependence and confi-dence on traditional medical practitioners Bhopa, Jaankar, devala etc is the result of faith and trust among patients. Through them, the tribals relate their needs to supernatural powers and ask for assistance and clemency.

The bifurcation between traditional and modern medical systems still obtains in the anthropological literature, in spite of its erroneous and deceptive representation. All traditional medical systems are not irrational and not alike and even biomedicine has its own tradition. It was believed by earlier authors that these two systems are discrete and biomedicine will replace traditional medical systems over time (Foster and Anderson, 1978). This study is one of many that 
show that traditional medical practices as well as biomedicine co-exist. The concept of medical pluralism relates the existence of more than one medical system in societies (Leslie, 1979; Elling, 1980). Within this concept the focus remains on medical traditions as bounded systems rather than as social institution. As traditional medical system have survived in this area for such a long time, its therapeutic value and what is retainable of traditional system and how these can be upgraded through education, licensing and incorporation in to state health planning becomes important. The work force represented by traditional practitioners and traditional birth attendants is a potentially important resource for the delivery of primary health care. In many developing countries, medical doctors are less as compared to traditional practitioners. In Ghana, for example, the medical doctor/total population ratio is 1: 20,000 compared to the traditional practitioners/total population ratio is $1: 2,000$. Over two-thirds of the births in the world are delivered by local and traditional midwives or births attendants. The state health programmes are well intended but lack anthropological consultation. As a consequence, the traditional medicinal care practiced in the area having both herbal as well as ritual form of curing is not considered important. The cultural importance of ritual cure and role of medicinal plants (their properties as they relate to healing, their symbolic values and their procurement from environment) in the traditional medical system of tribals is of great value. It was recorded during field work that there are large number of illnesses where oral application of herbal preparations are a frequent part of the treatment (e.g fever, dysentery diarrhoea, malaria, cough and cold, eye ailments, Guinea worm (Nadu), stomachache etc. (Bhasin, 2005). However, at some point the tribal see the limits of such phytotherapeutic forms of treatment. Any illness that is associated with severe pain, long lasting and does not respond to any herb requires help of the supernatural. The tribals relate their ritual needs to supernatural powers and ask for help and forgiveness. The state sponsored medical system do not look "at indigenous medicine" as a whole and fail to see the socio-cultural basis of its uses.

The main strength of the Traditional Medical System (TMS) of tribals is its capacity to stand as psycho support system. The explanatory model of TMS greatly emphasises the notion of disharmony as a cause due to man's relations with the supernatural powers and other bodily connected disturbances caused by drinking and eating wrong things. Transferability and transgressionality of supernatural wrath to the members of society makes it a powerful force in social control, a great help in maintenance of social control.

Tribals epidemiological profile advocate for provision of preventing services for diseases like gastro-enteric infections, pulmonary infections and malaria. These problems have already been tackled in other countries by starting welfare state health services. In India too the state health services have been functioning but are less effective or have overlooked the fact that aggregate health levels cannot improve without preventive measures, such as vaccination and environmental sanitation.

The level of knowledge about causes of illness and its treatment is of low order among tribals. The main concern of the authorities should be to increase these awareness levels, so that efficacy of existing services could be significantly enhanced.

It has been seen that in India, making health services available free, in principle, to tribals has not paid of and has not proved to be the best conduit for health improvement. In practice, bulks of tribals by no means are able to have access to these state sponsored health centres, nor do they feel the necessity to go there. The network of public health services that is in reality obtainable to tribals is decidedly lacking in terms of infrastructure and personnel. Still where such facilities are available and functioning as should be, tribals either go to faith healers or to a private practitioner (trained or untrained). It appears there is really something missing in the character of the health services. The fact that even the poor tribals use private health facilities in preference to Primary Health Centre is an indication of the failure of the public health delivery system.

The political circumstances under which biomedicine took roots in India were significant. The shape and course, it has taken as a colonial legacy reflects imperial impact. The colonial government, in the face of enormous public pressure was compelled to expand health services. However, the beneficiaries were the privileged classes and major urban populations. A similar trend was carried over after Independence. After Independence, the government took over the 
planning framework of the Bhore Committee, rather than their own National Planning Committee's public health proposals. The work of the Director General of Health Services (DGHS) was taken over by the Ministry of Health and Family Welfare, mostly managed by cadres of the IAS. These officers were merely administrators and lacked the required competence of managerial physicians and experiences of technological fields. The Rural Health Planning Services; the formulation of Universal Programme of Immunization (UIP); and launching Area Projects covering 65 districts of the country became the responsibility of the Department of Family Planning, that was outside the purview of the DGHS. The performance at Union level has had far reaching effect on the delivery of the health services at the State level. The State government is responsible for the actual implementation of the various health policies. Unfortunately, the administrators at the State level also failed to deliver the goods. They failed in implementation of various programmes of education and training of various types of health workers and of providing research support to different programmes. These services are being managed by administrators who lack high level of technological and epidemiological input required for the posts resulting in set backs in many health and family planning programmes.

Factually the role of the state is important in providing health care. However, until health awareness at the household and community level improves, success in upgrading health services, though necessary will be of little service. Education is an effective catalyst in bringing about changes in social and behavioural attitudes, not only towards health and medicine but also in the 'social intermediation' process. Kabir and Krishnan (1998) have defined 'social intermediation' in context of health transition as, "interventions at different levels of the society by various agents to change social and behavioural attitudes within the prevailing social environment for achieving desired health outcomes for the society". Their study of Kerala indicates "how education of the lower castes along with other economic changes altered the social environment itself whereby the attitudes of the lower castes began to change towards access to health, education and public employment"(ibid. p.242). Social intermediation proved to be important for the success of health programmes like vaccination against smallpox, in integrating women into the healthcare system, in initiating changes in the attitudes of the population towards health and medicine and in providing access to the disadvantaged castes in Travencore.

Cultural and social factors erect the barriers to the utilisation of health care. Resorting to various intermediation measures may break these barriers. It has been reported that after the formation of Kerala state, the rapid decline in infant mortality and fertility rates was attributed to the intensification of programmes on child and maternal health in these areas since then. The establishment of separate women's and children's hospitals manned by female health personnel is probably a first step in finding a solution to the problems of maternal and child health, at least in the initial stages of health development in the backward states (Kabir and Krishnan, 1998: 26061). Long period of schooling of girls and subsequent high literacy rates also contributed to these changes. Education also facilitates the training of the medical and paramedical personnel from within the region. Health and education should be paired and developed side by side.

The important question is, are the lessons from Kerala's health transition relevant for the tribals of Rajasthan? Is the concept of social intermediation useful in this case? The economic and social conditions of tribals are different from the conditions that prevailed in Travencore in 19 th century. However, many of the factors involved in Kerala's health transition are similar to tribals of Rajasthan. Like Kerala's health transition, for tribals of Rajasthan also, the improvement in health status entails not only medical issues but also economic and social problems. While designing a health strategy for these tribals all these issues need to be tackled. In addition, distinction between supply of and access to health care should abide by. Access is not coterminous with supply. Access implies locational, economic and social access; access also implies access to quality health care as opposed to the mere physical presence of a health care facility. Among tribals of Rajasthan even locational access, let alone economic and social access, is beyond the majority of the population as is evidenced by the data on the distribution of health care facilities(Bhasin ,2005). Where, these facilities were provided for, economic and social access was not a reality as it lacked changes in the basic social environment. In this connection, the demand creation and 'right to access' are as 
essential as the extension of health care facilities for health transition. The most important need among tribals is to bring about changes in the social attitude to biomedicine and health care. Given the social environment of the tribal areas, this could be achieved by social intervention to overcome social or psychological resistance. In these areas caste rigidities and social stratification are still rampant and social access is still a critical factor in access to health.

\section{NOTE}

1. The theory of "inverse care law"is based on a study of resource allocation for health services in Wales, England, nearly 30 years before government policy began to address the situation.

\section{REFERENCES}

Adams, V. 1992. "Reconstituted relations of production in Sherpa tourism." Ann. Tourism Res., 19

Alter, G., and J. C. Riley. 1989. "Frailty, sickness and death: Models of morbidity and mortality in historical populations." Population Studies, 43: 2546.

Atkinson, S. J. and M. F. Farias. 1995 "Perceptions of risk during pregnancy amongst urban women in northeast Brazil." Social Science and Medicine, 41: $1577-1586$.

Babb, Lawrence. 1975. "Heat and Control in Chhattisgarh Ritual." Eastern Anthropologist, 26: 11-28.

Bardhan, A., S. K. Sinha, K. Gopinath and A. K. Brahmbhatt. 1989. A Diagnostic Study of Factors Responsible for Less or no Utilization of Health Facilities among the Bhils of Madhya Pradesh. PAC Report, New Delhi: NIHFW.

Basu, S. 1990. "Anthropological Approach to Tribal Health", (pp. 131-142) in Ashish Bose, Tiplut Nangbri and Nikhlesh Kumar (eds.), Tribal Demography and Development in North East India. Delhi: B. R. Publishing Corporation.

Beals, A. 1980. "Stratigies of resort to curers in South India”, (Pp.194-195) in C. Leslie (ed.), Asian Medical Systems. Berkely: University of California Press.

Berreman, Gerald D. 1964. "Brahmanism and Shamanism in Pahari Religion", in E.B. Harper(ed.). Religion in South Asia. Seattle: University of Washington Press.

Bhasin,V. 1977. "Medical Pluralism and Health Services in Ladakh." J. Soc. Sci., 1: 43-69.

Bhasin, V. 1989. Ecology, Culture and Change: Tribals of Sikkim Himalayas. New Delhi: Inter-India Publications.

Bhasin, V. 1990. Habitat, Habitation and Health in Himalayas. A Comparitive Study of the Peoples of Sikkim and Gaddis of Himachal Pradesh. Delhi: Kamla-Raj Enterprises.

Bhasin,V. 1993. "Social Dimensions of Politics: The Case of Tribal Democracy in Sikkim." J. Hum. Ecol., 4: 63-78.
Bhasin, V. 1997. "The human settlements and health status in Sikkim", (Pp. 153-188 ) in K. C. Mahanta (ed.), People of the Himalayas. Delhi: Kamla-Raj Enterprises.

Bhasin, V. 1999. Tribals of Ladakh: Ecology, Human Settlements and Health. Delhi: Kamla-Raj Enterprises.

Bhasin, V. 2000. "Way of Life the Among Sahariyas of Rajasthan." J. Hum. Ecol., 11(6): 411-427.

Bhasin, V. 2002. "Traditional Medicine Among Tribals of Rajasthan." J. Soc. Sci., 6(3): 153-172.

Bhasin, V. 2003. "Habitat, Economy and Society: The Kathodis of Rajasthan." J. Hum. Ecol., 14(1): 1-21.

Bhasin, V. 2004a. "Sexual Illnesses and Underutilization of Biomedicine Among Tribal Women of Rajasthan." Anthropologist, 6(1): 1-12.

Bhasin, V. 2004b. "Oral Health Behaviour Among Bhils of Rajasthan." J. Soc. Sci. 8(1): 1-5.

Bhasin, V. 2005. Medical Anthropology: Tribals of Rajasthan. Delhi: Kamla-Raj Enterprises.

Bhatia, J. C. 1986. A Study of Maternal Mortality in Anantpur District, Andhra Pradesh, India. Banglore: Indian Institute of Management.

Bicego, G. and O. B. Ahmad. 1996. Infant and Child Mortality. Demographic and Health Surveys Comparative Studies No. 20. Calverton, MD: Macro International.

Bongaarts, J. and P.C. Potter. 1983. Fertility, Biology and Behaviour: An Analysis of the Proximate Determinants. New York: Academic Press.

Browner, C. H., and N. Press. 1996. "The production of authoritative knowledge in American prenatal care." Medical Anthropology Quartterly, 10: 156.

Caldwell, B.1966. "The family and demographic change in Sri Lanka." Health Transition Rev., 6 (Suppl.): 45-60

Camaroff, Jean. 1981. "Healing and Cultural Transformation: The Swana of Southern Africa." Social Science and Medicine, 15 B: 367-378.

Camaroff, Jean. 1983. "The Defectiveness of Symbols or Symbols of Defectiveness? On the Cultural Analysis of Medical Systems." Culture, Medicine and Psychiatry, 7: 3-20.

Chambers, R. and R. Longhurst. 1986. "Trees, Season and the Poor." IDS Bulletin, 17 (3)

Chambers, Robert. 1989. "Vulnerability: How the Poor Cope." IDS Bulletin 20(2):1.

Chambers, R., N.C. Saxena and T. Shah. 1989. To the Hands of the Poor: Water and Tress. London: Intermediate Technology Publications.

Chauhan, B.R. 1967. A Rajasthani Village. New Delhi: Vir Publishing House.

Chesi, Gert. 1981. Faith Healers in the Philippines. Australia, Worgi: Perlinger Verlag.

Cosminsky, S. 1977. "Impact of methods on the analysis of illness concept in a Guatemalan community." Soc. Sci. Med., 11: 325.

Cosminsky, S. 1980. "Medical pluralism on a Guatemalan Plantation." Soc. Sci. Med., 14B: 267-278.

Danforth, Loring M. 1989. Firewalking and Religious Healing. Princeton: Princeton University Press.

Elling, R. 1979. "Medical sociology: Traditional and modern medical system", H. Fabrega and P. Manning (eds.), Illness Episodes, Illness Security Treatment in Pluralistic Setting. Social Science and Medicine, 13 B: 41-51. 
Elling, R. 1980. "Medical sociology: Traditional and modern medical system." Special Edition of Soc. Sci. Med., 15 A (2).

Evans-Pritchard, E.E. 1937. Witchcraft, Oracles and Magic among the Azande. Oxford: Clarendon Press.

Fabrega, H. and P. Manning. 1979. "Illness Episodes, Illness Security Treatment in pluralistic Setting." Social Science and Medicine, 13 B: 41-51.

Falkner, Frank. 1983 "Health Inequalities in European Countries." Milbank Memorial Fund Quarterly/ Health and Society, 61: 430-44.

Falkner, Frank (Ed.): Health Inequalities in European Countries. Aldershpot: Gower (1989).

Feldman, J. J. 1983. "Work ability of the aged under conditions of improving mortality." Milbank Memorial Fund Quarterly/Health and Society, 61: 430-44.

Florez, C.E. and D.P. Hogan 1990. "Women's status and infant mortality in rural Columbia. Soc. Biol., 37(34): $188-203$

Foster, G.M. and B.G. Anderson. 1978. Medical Anthropology. New York Chichester Brisbane, Toronto: John Wiley and Sons.

Franzmann, Majella. 2000. Women and Religion. Oxford: Oxford University Press.

Freed Stanley, A and R. S. Freed 1964. "Spirit possession as a illness in a north Indian village." Ethnology, 3(2): 152-171.

Freedman, D.S., A. Thompton and L. Wallisch 1981. "Age at first birth and family size: Evidence from a longitudinal study." Soc. Biol., 28: 217.

Geertz, C.1973. The Interpretation of Culture. New York: Basic Books.

Gonzales, N.S. 1966. "Health behaviour in cross-cultural perspective: A Guatemalan example." Human Organization, 25: 122.

Harper, E.B. 1969. "Fear and the Status of the Women." South Western Journal of Anthropology, 25: 81-95.

Hart, J. T. 1971. "The inverse care law." Lancet, 1(7696): 405-412.

Haviland, William A.2003. Anthropology. 10th Edn. Belmont, CA: Wadsworth.

Jeffery, P., R. Jeffery and A. Lyon 1988. Labour Pains and Labour Power: Women and Childbearing in India. London: Zed Books, Ltd.

Jones, K. B. 1993. Compassionate Authority: Democracy and the Representation of Women. London: Routtedge.

Jones, Rex L. 1976. "Spirit possession and society in Nepal", in T. Hitchcock, L. Rex and L. Jones (eds.), Spirit Possession in Nepal Himalayas. New Delhi: Vikas Publishing House.

Jordan, B. 1993. Birth in Four Cultures: A Cross-cultural Investigation of Childbirth in Yucatan, Holland, Sweden and the United States. Prospects Heights. IL: Waveland Press.

Jordan, B. 1997. "Authoritative knowledge and its construction", (pp. 55-79) in R. Davis-Floyd and C. F. Sargent (eds.), Childbirth and Authoritative Knowledge: Cross-Cultural Perspectives. Berkeley: University of California Press.

Kabir, M and T. N. Krishnan. 1998. "Social Intermediation and Health Change: Lessons From Kerala", in M. Das Gupta, Lincoln C. Chen and T. N. Krishnan (eds.), Health, Poverty and Development in India. Delhi: Oxford University Press.
Krishnan, T. N. 1985. "Health Statistic in Kerala State, India", in S. Halstead, K. Warren and J. Walsh (eds.), Good Health at Low Cost. New York: Rockefeller Foundation.

Kumar, B. G. and A. Vaidyanathan. 1988. "Morbidity in India: Some problems of measurement, interpretation and analysis." Paper presented to 6th Annual Convention of the Indian Society for Medical Statistics, National Seminar on Statistics in Medicine, Health and Nutrition, 27-29 October (1988).

Lambert, Helen. 1992. "The cultural logic of Indian medicine: Prognosis and Etiology in Rajasthani Popular Therapeutics".Social Science and Medicine, 34(10): 1069-1076.

Landy, D. 1974. "Traditional curers under the impact of western medicine." Amer. Ethnology, 1: 103.

Leslie, C. 1979. "Medical Anthropology: Medical pluralism." Special Edition of Soc. Sci. Med., 14 B (4)

Levi-Strauss, C. 1967. Structural Anthropology. New York: Doubleday.

Lunderberg, Olle. 1991. "Causal explanations for class inequality in health. An empirical analysis." Social Science and Medicine, 32: 385-393.

Magadi, M.A., N.J. Madise and R.N. Rodrigues 2000. "Frequency and timing of antenatal care in Kenya: explaining variations between women of different communities." Soc. Sci. Med., 51 (4): 551-561.

Malvi, B.L. 1980. "Venereal disease in Dungarpur District", in N.N. Vyas and R.S. Mann (eds.), Disease, Culture, Contact and Tribals. Udaipur: TRI (1980)

Manning, P and H. Fabrega Jr. 1973. "The experiences of self and body: Health and illness in Chiapas highlands", (P. 290) in G. Psathas (ed.), Phenomenological Sociology. New York: Wiley.

Momsen, J.H. 1999. Women and Development in the Third World. New York: Routledge.

Mukherjee, D. P. and S. K. Nandy. 1986. "Anthropology of Tribal Health: The Case of Asurin Netarhat Plateau", in B. Chaudhari (ed.), Tribal Health, SocioCultural Dimensions. New Delhi: Inter India Publication.

Murray, C. J. L. 1998. "Epidemiological and Morbidity transitions in India", in: M. Dasgupta, Lincoln C. Chen and T. N. Krishnan (eds), Health, Poverty and Development in India. Delhi: Oxford University Press.

Murray, C. J. L., and L. C. Chen. 1990. "A conceptual approach to morbidity in the health transitions." Harvard Center for Population and Development Studies, Working Paper.

Murray, C. J. L., G. Yang, and X. Qiao. 1992. "Levels, patterns and causes of adult mortality", in: R. G. Feachem, T.. Kjellstrom, C. J. L. Murray, M. Over and M. Philips (eds.), The Health of Adults in the Developing World. New York: Oxford University Press.

Nabokov, Isabella. 2000. Religion Against the Self. Oxford: Oxford University Press.

Neumann, Alferd K., J.C.Bhatia, S. Andrews, and A.K.S.Murphy. 1971. "Role of the indigenous medicine practitioners in two areas of India- repot of a study". Soc. Sci. Med., 5: 137-149.

Nichter, M. and M. Nichter. 1983. 'The ethnophysiology and folk dietet of pregnancy: Acase study from South India." Human Organization, 42: 235-246.

Nichter, M. 1989. "Lay perceptions of medicine: A south 
Indian case study", (pp. 187-213) in M. Nichter (ed.), Anthropology and International: South Asian Case Studies Boston: Kluwer Academic Publishers.

Nichter, M. 1992. "Introduction", in M. Nichter (ed.), Anthropological Approaches to the Study of Ethnomedicine. Tuscon: Gordon and Breach Science Publishers

Opler, Morris, E. 1958. "Spirit Possession in a rural area of north India" (Pp.553-566) in Less William A. Evon and Z. Vogt (eds.), Readers in Comparative Religion: An Anthropological Approach. White Plains, New York: Row Peterson and Co.

Ortner, Sherry 1974. Is female to male as nature is to culture. in Michelle Rosaldo and L. Lamphere (eds.), Women, Culture and Society. Stanford: Stanford University Press.

Panikar, P. G. K. and C. R. Soman. 1984. Health Status of Kerala: The Paradox of Economic Backwardness and Health Development. Trivandrum: Centre for Development Studies.

Pedersen, D. and V. Bariffati. 1989. "Healers, deities, saints and doctors: elements for the analysis of medical systems." Soc. Sci. Med., 29(4): 487-496.

Press, I. 1978. "Urban fold medicine." Am. Anthrop, 80: 71.

Rapp, R. 1993. "Accounting for amniocentesis", (Pp. 55-76) in S. Linden-Baum and M. Locks (eds.), Knowledge, Power and Practice: The Anthropology of Medicine and Everyday Life. Berkeley: University of California Press.

Rappaport, R. 1979. Ecology, Meaning and Religion. California: North Atlantic Books

Riley, N.E. 1997. "Gender, power and population change." Population Bulletin, 52 (1):1-48.

Rizvi, S. N. H. 1986. "Health Practices of the JaunsarisA Socio Cultural Analysis", in B. Chaudhari (ed.), Tribal Health, Socio-Cultural Dimensions. New Delhi: Inter India Publication.

Romanucci, R. 1980. "On the researching of lost images." Anthropology and Humanism Quaterly, 5 (1): 14-20.

Romanucci, Ross. 1997. "Creativity in illness: Methodology, linkages to the logic and language Of science in folk pursuit of health in Central Italy", in Lola Romanucci-Ross, Daniel E. Moerman and Laurence R. Tancredi (eds), The Anthropology of Medicine from Culture to Method. Connecticut: Bergin and Garvey.

Roy Burman, B. K. 1986. "Morbidity and Nutritional Status of the Scheduled Tribes of India", in B. Chaudhari (ed.), Tribal Health, Socio-Cultural Dimensions. New Delhi: Inter India Publication.

Rustein, S. O. 1984. "Socio-economic Differentials in Infant and Child Mortality." World Fertility Survey
Comparative Studies No. 43. Voorburg: International Statistical Institute.

Sargent, C. and G. Bascope. 1996. "Ways of knowing about birth in three cultures." Medical Anthropology Quarterly, 10: 213-236.

Schwartz, L.R. (aka Lola-Romanucci-Ros). 1969. "The hierarchy of resort in curative practices: The Admiralty Island, Melanasia." J. Health and Social Behaviour, 10: 201-209.

Scott, John Wallach. 1988. Gender and the Politics of the History. New York: Columbia University Press.

Sen, Amartya. 1998. "Objectivity, Health and Policy", in M. Das Gupta, Lincoln C. Chen and T. N. Krishnan (eds.), Health, Poverty and Development in India. Delhi: Oxford University Press.

Sered, Susan: Priestess,Mother, Sacred Sister: Religion Dominated by Women. Oxford University Press (1994).

Sered, Susan.. 1998. Religiously doing gender: The Good women and the bad women in Israeli Ritual Discourse. Method and Theory in the Study of Religion.

Shanfelt, Robert. 2004. "Magic, Miracle, and Marvels in Anthropology." Ethnos, 69(3): 317-340.

Singh, V. and R.P. Pandey. 1982. "Plants used in religion and magico-religious beliefs in Rajasthan." J. Econ. Tax. Bot., 3: 273-278.

Spiro, M. 1967. Burnese Supernaturalism. Indiapoinlis: Bobbs-Merrill.

Thaddeus, S. and D. Maine. 1994. Too far to walk: Maternal mortality in context. Social Science and Medicine. 38: 1091-1110.

United Nations Development Programme UNDP, 227 1998

Vyas, M.K.: Social factors of venereal diseases: Some aspects. In: Disease, Culture, Contact and Tribals. N.N Vyas and R.S. Mann (Eds.). Udaipur: TRI (1980).

Vyas, N. N. 1980. Bondage and Exploitation in Tribal India. Jaipur and Delhi: Rawat Publications.

Vyas, N. N. and R. S. Mann (Eds.). 1980. Indian Tribes in Trasition. Jaipur and Delhi: Rawat Publications.

Wallace, Ruth A. 1977. "The Mosaic of Research on Religion: where are the Women?" Journal for the Scientific Study of Religion.

Wagner, R.M.1978. "Traditional and modern medicine as reflected in contemporary Peyotist practices", in B. Velimirovic (ed.), Modern Medicine and Medical Anthropology in the United States - Mexico Border Populations. Washington D.C.: Pan American Health Organization, Scientific Publication Paho No. 359.

WHO. 1989. Preventing Maternal Deaths. Geneva: World Health Organization.

Wijsen, F. and R.E.S. Tanner. 2001. The Recreation of Cultural Identity. in press (2001). 